\title{
Prototyping with your hands: the many roles of gesture in the communication of design concepts
}

\author{
Cash, Philip; Maier, Anja
}

Published in:

Journal of Engineering Design

Link to article, DOI:

$10.1080 / 09544828.2015 .1126702$

Publication date:

2016

Document Version

Peer reviewed version

Link back to DTU Orbit

Citation (APA):

Cash, P., \& Maier, A. (2016). Prototyping with your hands: the many roles of gesture in the communication of design concepts. Journal of Engineering Design, 27(1-3), 118-145.

https://doi.org/10.1080/09544828.2015.1126702

\section{General rights}

Copyright and moral rights for the publications made accessible in the public portal are retained by the authors and/or other copyright owners and it is a condition of accessing publications that users recognise and abide by the legal requirements associated with these rights.

- Users may download and print one copy of any publication from the public portal for the purpose of private study or research.

- You may not further distribute the material or use it for any profit-making activity or commercial gain

- You may freely distribute the URL identifying the publication in the public portal

If you believe that this document breaches copyright please contact us providing details, and we will remove access to the work immediately and investigate your claim 


\title{
Prototyping with Your Hands: The Many Roles of Gesture in the Communication of Design Concepts
}

\begin{abstract}
There is an on-going focus exploring the use of gesture in design situations, however, there are still significant questions as to how this is related to the understanding and communication of design concepts. This work explores the use of gesture through observing and video-coding four teams of engineering graduates during an ideation session. This was used to detail the relationship between the FBS elements and individual gestures as well as to identify archetypal gesture sequences - compound reflective, compound directed one-way, mirroring, and modification. Gesture sequences occurred at critical periods during the design session, such as, idea evolution, and developing shared understanding. They are used to act out design concepts, repeat and learn from sequences, and establish shared understanding. Finally, a number of implications are identified for both researchers and those seeking to support practice.
\end{abstract}

Keywords: Design understanding; mechanical product design; protocol analysis; empirical study; human creativity

\section{Philip Cash and Anja Maier}

Department Of Management Engineering, DTU Technical University of Denmark, Lyngby, Denmark

To cite this article: Philip Cash \& Anja Maier (2016): Prototyping with your hands: the many roles of gesture in the communication of design concepts, Journal of Engineering Design

To link to this article: http://dx.doi.org/10.1080/09544828.2015.1126702 


\section{Introduction}

Gesture fulfils a number of important roles in design, from supporting communication and cognition to being used as the basis for data-handling and user support (Eris, Martelaro, \& Badke-Schaub, 2014). However, significant challenges remain in describing and understanding gesture's varied roles in the evolution and communication of design concepts (Yasui, 2013). This is partially due to gesture's complex relationship with a number of other communication modalities (Luck, 2010), and its various roles (Becvar, Hollan, \& Hutchins, 2008; McNeill, 1992) in design (Eris et al., 2014).

Gesture exists as part of a dynamic, multimodal interaction between the designer and the outside world, involving, for example, gaze and vocalisation (Ariff, Eris, \& BadkeSchaub, 2013; Murphy, Ivarsson, \& Lymer, 2012). Prior works have described the use of both individual gestures e.g. Eris et al. (2014), and gestural sequences e.g. Yasui (2013), as core elements in the progression of conceptualisation and design conversations. However, few works have examined the use of gestural sequences, their extent, and their roles in explaining mechanical systems and artefacts, where complex mechanical relationships are common. Further, questions remain as to how gestures are combined in this context and whether archetypal sequences exist across design tasks (Luck, 2010; J. Tang, 1991). In particular, Yasui (2013) described gestural sequences with respect to idea construction surrounding the design of a short film, and proposed their commonality across contexts. As such, this paper explicitly builds on this to refine the identification of archetypal gesture sequences and examine their roles in relation to an electro-mechanical design task. The findings bring together and extend prior characterisations of archetypal gesture sequences and their varied roles in design conversations. The aim of developing this understanding is to provide a foundation for gestural training and communication support for designers and engineers in collaborative design scenarios. In particular, the ability of gesture to support the 
representation of dynamic movement in space, fluidly and in relation to other design artefacts opens a range of possibilities for developing a gestural design language, beyond traditional sketching and physical prototyping.

This is investigated during an ideation and development activity in a co-located collaborative design setting, resulting in three main contributions. First, by relating single gestures to the Function Behaviour Structure (FBS) framework (Gero \& Kannengiesser, 2004; Gero, 1990), we explicitly address one of the issues highlighted by Eris et al. (2014) in their discussion of Tang et al.'s (2011) work. Second, by extending the characterisation of archetypal sequences of gestures, we contribute to the integration of understanding across design contexts, linking explicitly to Yasui (2013). Third, the identified gesture sequences (compound reflective, compound directed, mirroring, modification) are examined in detail via a qualitative analysis of concurrent gesture, speech, and other body language, with a particular focus on the communication of interactions between the functions and between the parts of the device to be designed. The findings form the basis for a number of implications for further research aimed at supporting designers and engineers in communicating mechanical systems and functional/part interactions. An overview of gesture and its relation to current design research is next presented in Section 2. The study method is then described (Section 3) and in depth results presented and analysed (Section 4). Then, implications for both research and practice are identified in Section 5 before conclusions are drawn and a number of key avenues for further research are proposed (Section 6).

\section{Background}

To explore gesture in the design context, and in particular with respect to design specific concepts, two areas are considered: the wider nature of gesture (Section 2.1) and gesture in relation to design (Section 2.2). 


\subsection{Gesture}

Gesture is a fundamental part of human behaviour, playing a role in both cognition and communication (McNeill, 1992; Roth, 2001). Humans gesture when in conversation with others, on the telephone, or even when alone (Goldin-Meadow, 1999; McNeill, 1992). As such, gesture studies form a wide-ranging interdisciplinary field with contributors including anthropology, art, artificial intelligence, communication sciences, computer science, dance, linguistics, psychology, sociology, and theatre. However, gesture is not a universal language because it appeals to the recipients' own knowledge, which is informed by e.g. culture, subject specific information, and experience (LeBaron \& Streeck, 2000). In particular, Archer (1997) highlights differences in gesture use across cultures. As such, gesture must always be considered in context and with respect to its purpose in the wider conversation. For example, although two designers from different cultures might not share a common understanding of a social gesture (as illustrated by Archer (1997)) they might understand a gesture related to the interaction between two gears due to their common training as designers and experience in the conversation and task leading up to that point (as illustrated by Bekker et al.'s (1995) categorisation of common gestures in the design of groupware).

Visser and Maher (2011) highlight the contributions from psychology of gesture and human computer interaction as relevant for the design researcher. For example, GoldinMeadow (1999) discusses how, when used in conjunction with speech, gesture allows the display of thoughts or ideas not (easily) expressed verbally, while also providing a tool reducing cognitive load. Gesture expression supports reasoning by grounding it in the physical (Becvar et al., 2008). Due to gestures fundamental link to the underlying thought process via embodied cognition it is possible to use gesture as a window into the cognitive process itself (Becvar et al., 2008; Wilson, 2002). However, significant questions remain in how specific gestural elements link to cognition, with different perspectives on how gestures 
should be interpreted in this context (Becvar et al., 2008; McNeill, 2000). Becvar et al. explain that exploring gesture during interaction permits a glimpse into how engineers understand design concepts.

In terms of communication, gesture constitutes one of many modes employed during human interaction (Becvar et al., 2008; Kendon \& Muller, 2001). In particular, it is closely related to gaze, speech, and body position, and is typically encountered in this multimodal context (Luck, 2010, 2014). Gesture can embody a wide range of information from tempo or beat to dynamic interactions (Goldin-Meadow, 1999). For example, consider the designer communicating the rhythmic movement of a piston. Here, much of the impact of gesture lies in the direct relationship between the content of the communication and its physical embodiment, unlike the often ambiguous and arbitrarily assigned meaning of symbolic language (Becvar et al., 2008). For example, Mitra \& Acharya (2007) highlight the role of gesture in informing rich yet efficient human computer interaction, and Behoora and Tucker (2015) describe technical approaches to classifying body language in order to detect emotional states.

Bringing these perspectives together, the International Society for Gesture Studies (ISGS) provides a broad definition of gesture research as 'concerning the use of the hands and other parts of the body for communicative purposes' (ISGS, 2013) ${ }^{1}$. Decomposing this further, there has been a number of attempts at classifying generic types of gesture, reviewed and discussed at length by Goldin-Meadow (1999, 2005). The most widely accepted classification is that of McNeill (1992) who describes gestures as one of four possible classes: iconic, metaphoric, deictic and beat. Using this overall definition and classification scheme, it is possible to explore the extent of existing gesture research specifically related to design.

\footnotetext{
${ }^{1}$ International Society for Gesture Studies (ISGS), founded in 2002, http://www.gesturestudies.com/, 01.12 .2013
} 


\subsection{Gesture in Design}

Studies of designers in collaborative design situations - face-to-face or remote - have primarily focused on verbal protocols or sketching (Cross, Dorst, \& Roozenburg, 1992; Maier \& Kleinsmann, 2013; Rodgers, 2012), with fewer extant studies of gesture, as highlighted in the reviews of Visser and Maher (2011), and Eris et al. (2014). Many of the studies focused on design related gesture fall in the domain of Human Computer Interaction (HCI). For example, the functions and implications of gesture on the design of HCI devices and gesture recognition e.g. robot programming and control (Waldherr, Romero, \& Thrun, 2000), manipulation of complex simulation and medical data (Wachs, Kölsch, Stern, \& Edan, 2011), and helping functionally handicapped people (Chang, Chen, \& Huang, 2011). In the design domain a number of research foci have emerged, generally falling into one of two schools of thought, which we refer to as the categorical and contextual.

In the categorical school, authors have adopted taxonomic approaches. For example, Visser $(2009,2010)$ proposes a classification of general gesture roles, in their study of design meetings. Other important works in this school include Streeck (2008), Bekker et al. (1995) and Peter et al. (2013) who respectively, examine gesture use in the architectural domain, the development of gesture compatible groupware, and gesture in relation to physical artefacts. Through these works individual gestures and their use are categorised and grouped in order to provide generalizable frameworks. For example, from the cognitive science perspective, Tversky (2011) describes how visual communications abstract and schematise information in much the same way as written language, building up from base units, such as, vertical motion in space. In design this type of approach can support the systematic analysis of how gesture interfaces with other aspects of design work. This is most clearly illustrated by the recent work of Eris et al. (2014) who examine how gesture is used to relate to design sketches. The 
main categorisations used for individual gestures in the design domain are summarised in Table 1. This also serves to highlight the diversity in the classifications used.

Table 1: Gesture classifications used in design research

\begin{tabular}{lllll}
\hline McNeill (1992) & Bekker et al. (1995) & Streeck (2008) & Visser (2009) & Eris et al. (2014) \\
\hline Iconic & Kinetic & Modelling & Representation & At sketch content \\
Metaphoric & Spatial & Bounding & Organization & To enact scenario \\
Deictic & Point & Drawing & Focalization & At external content \\
Beat & Other & Handling & Modulation & Beat \\
& & Making & & \\
& Scaping & & \\
& Marking & & \\
& Self-marking & & \\
& & Model-world making & & \\
& &
\end{tabular}

Linking individual gestures together, the works of Bekker et al. (1995) and Yasui (2013) categorise gestural sequences associated with design. Bekker et al. describe four such sequences:

- Walkthrough: kinetic gestures used to describe interactions between user and product.

- List: pointing gestures used to facilitate a verbal list of items.

- Contrast: pointing gestures used to point from one concept to another.

- Emphasis: other gestures used to indicate an important part of the verbalisation.

Of these four, emphasis is the most general, being widely explored with respect to e.g. cohesive gesture, i.e. the use of gesture to link elements in a conversation and to add emphasis to points (Caso, Maricchiolo, \& Bonaiuto, 2006). Further, both list and contrast have received attention in relation to the use of pointing in design teams (Donovan, Heinemann, Matthews, \& Burr, 2011). However, walkthrough has proven significantly more complex when considering the wider context of design, i.e. not just user/product interactions. For example, Yasui (2013) proposes three distinct sequences related to idea development, building on the basic walkthrough concept:

- Full repetition: participants accept ideas in full by repeating gesture sequences.

- Partial repetition: participants partially accept ideas and propose new elements by modifying gesture sequences. 
- Modified repetition: participants partially accept and partially reject ideas while also proposing new elements by modifying gesture sequences.

In the contextual school, interaction, and gesture specifically, are considered to be resistant to abstract generalisation. The value of this perspective is illustrated most clearly by the works of Luck (2010, 2014), Donovan et al. (2011) and Murphy (2005). For example, Luck (2010) describes important sequences of multimodal interaction, narratively describing the roles of gesture, talk, and gaze to provide holistic understanding. This can be combined with some categorical elements to provide deep contextualisation of gesture use in a given domain. This is again illustrated by Luck (2014) who relates detailed situational narrations to the different roles described by Streeck (2008).

Although progress has been made in understanding gesture in design a number of significant questions remain. First, Luck $(2010,2014)$ points to the need to understand the complex relationship between gesture and its many roles in design. So far, this has primarily been explored in the architectural domain, and in the context of review type meetings (Luck, 2010, 2014; Murphy et al., 2012; Streeck, 2008; Visser, 2009). In particular, these meetings have centred on pre-prepared architectural drawings, and have focused on tasks substantially different from those likely to be encountered in the design of electro-mechanical systems. Second, where product design tasks have been the focus, such as, in the works of Donovan et al. (2011), and Eris et al. (2014), the relationship between specific design concepts and gesture use remains undefined. Specifically, Eris et al. (2014) express the need to relate gesture use to e.g. the Function Behaviour Structure framework. Further, all three articles in the AIEDAM special issue on gesture in design - including Donovan et al. (2011) - focus primarily on pointing (Visser \& Maher, 2011). Finally, the concept of strings or sequences of gestural actions (in conjunction with body language and gaze) have been highlighted as critical in design communication (Luck, 2014; Yasui, 2013) although significant questions 
remain as to their overall characterisation and roles across contexts. As such, this study explicitly builds on these works to explore the link between design concepts and gesture use in the context of designing an electro-mechanical device.

\section{Method}

Our study used an artificial design task that asked participants to develop a detailed concept for a remote controlled camera cradle to be mounted under an aerial vehicle and able to point the camera anywhere within a downward hemisphere. The initial brief was: "You are to design a universal camera mount for use on an aerial vehicle. The aerial vehicle is to be used by an amateur photographer, primarily to take still photos." An example solution is given in Figure 1 in order to illustrate the type of characteristics being discussed by the participants. This was not given to the participants and is included here purely to aid understanding of the design problem.

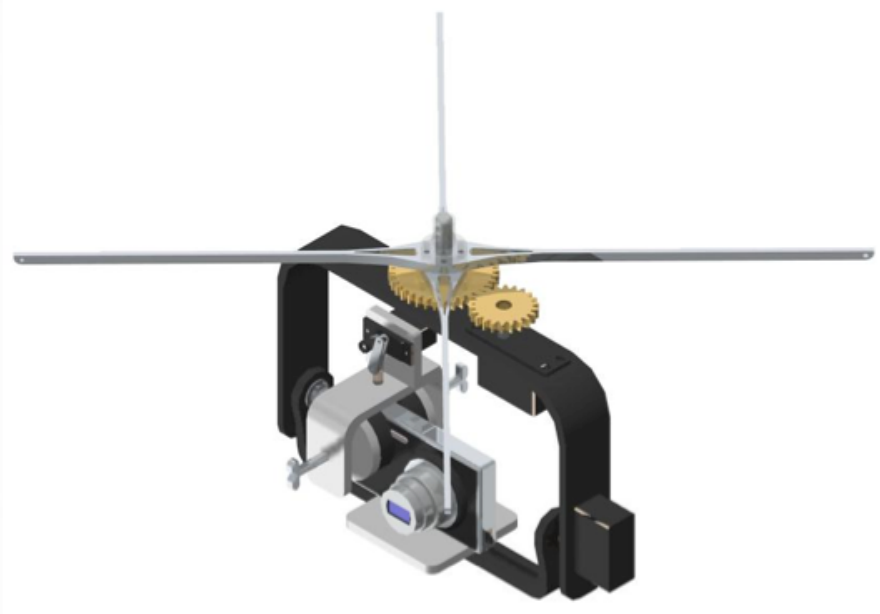

Figure 1: Example solution of the given task: design a universal camera mount for use on an aerial vehicle

The overall task was split into four phases of which the second was a team ideation session with three participants. The first phase allowed participants time to gather information individually, while subsequent phases were concerned with developing and selecting a final working concept. 
In the first phase participants were given 50 minutes to find and make note of relevant information for the given brief. Here, they had access to the Internet as well as a library of design textbooks and other technical documentation (although no participant used this physical media).

In the second phase (ideation), each team was tasked with generating as many ideas as possible whilst bearing in mind that the later stages of the study would require them to develop selected ideas into a final workable concept. The output of this activity was a list of as many ideas as possible, from which participants would each have to develop one idea further, i.e. participants would continue to work on the selected ideas in the following phases making feasibility important. Idea selection was carried out after the ideation phase was complete. Activity during the brainstorming was not constrained and occurred naturally within the context of the observation setup. The participants were only provided with blank paper, whiteboard, and logbooks, differentiating this study from works focused in the architectural domain where pre-prepared drawings formed the focus of the meeting (Luck, 2010, 2014; Visser, 2009). Further, gesture was not mentioned and participants were encouraged to work normally. The recorded brainstorming period lasted 50 minutes for all teams.

This task was formulated based on a number of prior studies. The first observed designers in practice in order to characterise activities associated with the development of consumer electro-mechanical products. This resulted in the identification of distinct phases framing ideation sessions: individual information seeking, ideation itself (referred to by the observed team as brainstorming), individual design development, and a review meeting. This formed the basis for the task description - matching similar briefs and product types observed in practice, the time allocated for each phase, the team size, and the ideation rules. A second set of studies then validated the utility of this specific task formulation by comparing students 
and practitioners engaged in this task and directly contrasting their activity with the above noted observation study from practice. This formulation of task type, ideation rules, and timing was further supported by comparison to prior works, such as, Howard et al.'s (2010) study of ideation in practice. As such, the task and outputs are both drawn from industrial context and have been explicitly baselined with respect to practice in multiple contexts (Cash et al., 2013).

Although gesture does occur during individual work, a group session was selected in order to more fully explore gesture use, and better reflect the situation in practice. Further, an ideation session was selected due to the frequent demand for the explanation and communication of ideas and other design concepts, ensuring sufficient depth for later analysis.

Each team was recorded via synchronised video cameras from three angles, giving complete coverage of the working space. This allowed all gestures to be fully recorded in conjunction with speech and other participant activity e.g. sketching. The recordings were then combined before being coded. Figure 2 gives an overview of the study layout and the camera views used.

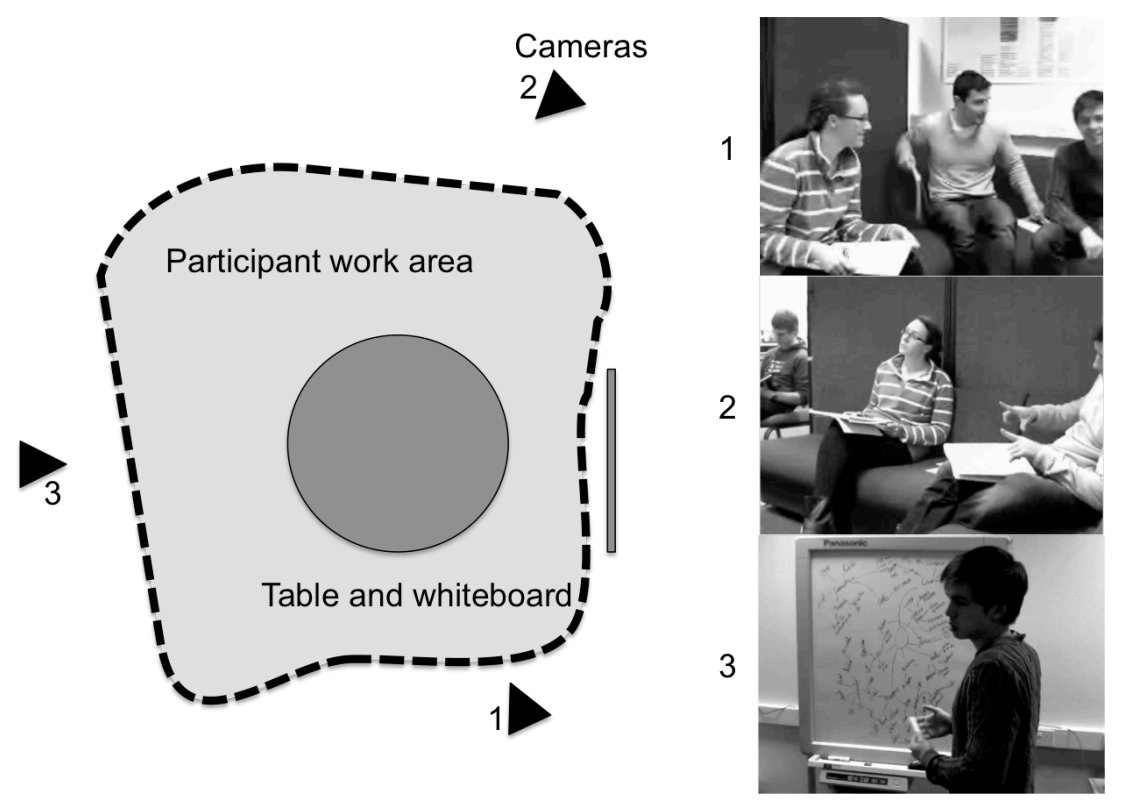

Figure 2: Technical setup and camera overview including example images 


\subsection{Population}

Due to the exploratory nature of this study a small sample size was selected in order to allow for in-depth qualitative coding and analysis. Statistical comparisons at this stage were considered inappropriate due to the lack of underlying theory on which to found a hypothesis based quantitative study. As such, this work falls in the theory building part of the research cycle (Eisenhardt \& Graebner, 2007).

The population was formed from twelve participants randomly allocated to four teams. The participants were themselves randomly selected from 40 final year engineering design Master's students on a product design course at a UK University. This meant that all participants had a mean of 4 years of design education and 10 months of industrial design experience. As such, the teams were balanced in terms of age, education level, subject area, and level of experience via random allocation. Students were considered appropriate due to their comparability to previous works also using students e.g. Yasui (2013), as well as their suitability given the generality of the aim stated in Section 1. Further, as there is no history of training engineers in the use of 'design' gestures, either in industry or academically, students were considered appropriate for this exploratory study. Although the use of students is a limitation in generalising to industry the major differentiating factor is that of generic design experience rather than any gesture related experience, due to its lack of study and application in practice.

A team size of three was selected based on the prior studies of practice described in Section 3 (Cash et al., 2013), as well as their wider representativeness, and the exclusion of possible side conversations. This is in line with some prior gesture studies (Yasui, 2013) and previous surveys of team size effects (Cash, Elias, Dekoninck, \& Culley, 2012). In particular dyads have been shown to display different generic communication behaviour to larger groups (Hackman \& Vidmar, 1970; Salas et al., 2008) while teams of three have been found 
to be analogous to teams of up to five people (Cash et al., 2012; Hackman \& Vidmar, 1970). However, there is little explicit guidance on the effects of team size on gesture. As such, comparison to prior works will make reference to studies of both dyads and triads in order to contextualise the findings from this study. Thus, this work adds to previous studies of dyads e.g. Eris et al. (2014) and Tang (1991), and links to studies of larger teams e.g. Yasui (2013), helping to explore the above noted phenomena in the design context.

\subsection{Coding and Analysis}

In the dynamic context of design, gesture fulfils a number of important functions in understanding and communicating the evolving artefact. In particular, representational gestures in concept generation and refinement form the major focus of this work due to their fundamental importance for overall design performance. In other words, how gestures are used to support kinaesthetic thinking and formulating/communicating engineering concepts (Eris et al., 2014; Streeck, 2009). Eris et al. (2014) highlight the importance of examining design specific gesture using the FBS framework, by reflecting on differences between their results and those of Tang et al. (2011). As such, gesture coding focused on two distinct aspects. First, gesture was considered in terms of its manifest target, either reflective or directed, and its type e.g. iconic (Section 3.2.1). Here, vocalisation is also considered in order to complement the gesture analysis. Second, FBS was used to describe the design element of the gestures (Section 3.2.2).

With the coding complete, analysis was split into two phases. First, the individual gesture level was considered in order to characterise a baseline for wider comparison of the qualitative findings (Section 4.1). Second, building on the work of Luck (2014) and Yasui (2013), important sequences of contiguous gestures were examined. These were distilled from the data inductively, before being described (Section 4.2). This supported an analysis and 
reflection on common gesture sequences. Further, it allowed for the integration of other modes of interaction occurring during these sequences, e.g. gaze and vocalisation.

The video data was compiled for each team and coded as a single combined record of the session. All codes were allocated to individual participants; allowing simultaneous action of multiple participants to be differentiated. For the purposes of team level analysis individual gestures were summed, i.e. two simultaneous gestures lasting three seconds each are recorded (at the team level) as six seconds of gesturing activity. Data was coded in four stages by two coders. First, each session was coded for individual gestures by both coders. Second, intercoder reliability was assessed and disagreements identified and discussed until a consensus was reached. The Kappa value at this stage was 0.76 prior to discussion and agreement of differences. Third, each session was coded for FBS by both coders. Finally, intercoder reliability was again assessed and disagreements between coders resolved in order to provide a robust dataset. Here the Kappa value was 0.96 prior to discussion and recoding.

\subsubsection{Coding Gesture}

Gestures require two elements to be fully described in manifest terms i.e. without latent interpretation of their cognitive function (Cash \& Snider, 2014): the target and the type. The target of the gesture denotes the focus of the participants' activity: towards themselves reflective - or towards one or more other participants - directed. In both cases prior research suggest that gestures support both cognitive and communicative aspects of the discussion (Goldin-Meadow, 2005; McNeill, 1992). However, they are differentiated here in order to distinguish gestures specifically targeted at other participants from those primarily intended for personal reflection. This extends prior works which have focused on directed gesturing e.g. Yasui (2013), to include reflective elements that have been shown to be important in other design activities e.g. sketching (Schön \& Wiggins, 1992). This is a key element in 
extending understanding of gestural sequences in design, and provides a foundation for possible training by explicitly acknowledging reflective practice as a part of design work.

Gesture target was coded based on hand movements, body posture, gaze, and vocalisation of the instigating participant, bringing together the holistic approach of e.g. Luck (2014) and the more technical characterisations used by e.g. Yasui (2013) and Behoora et al. (2015), as illustrated in Figure 3.

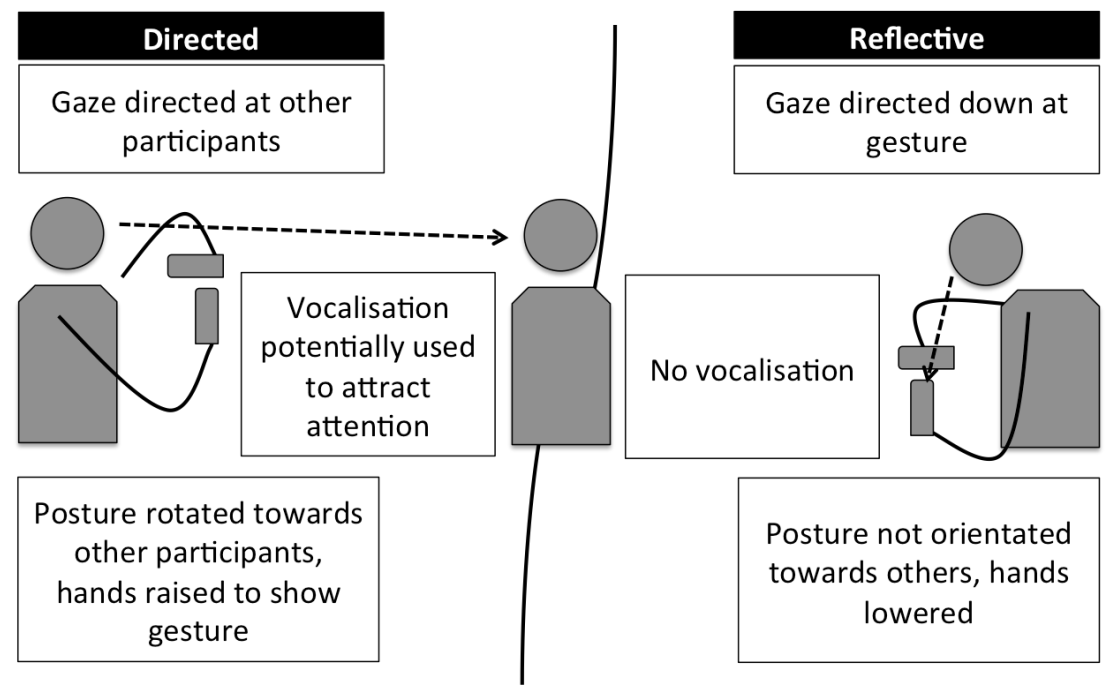

Figure 3: Example indicators used in coding gesture target including reflective and directed In terms of gesture type the schema of McNeill (1992) was adopted. However, 'cohesive' gestures were also included for completeness (Section 2.2). This allowed for a comprehensive description of individual gesture use. The coding consisted of two subgroups - target and type. Codes within each subgroup are complete and mutually exclusive, with each gesture allocated one code from each subgroup. For example, a gesture might be described as 'reflective' and 'iconic'. These codes are detailed in Table 2. Throughout, coding was started at the initiation of a gesture and stopped at the completion of a discrete gesture. Gesture start was defined as the hands moving from a neutral position. Similarly the gesture was considered to end when the hands once again resumed a neutral position. This approach is in line with the work of Eris et al. (2014). This analysis focused on hand movements to explore gestural sequences and complement and extend prior design research in this area (Section 2). 
However, as noted, body position, expression, gaze, and vocalisation were also considered in the qualitative analysis.

Table 2: Gesture codes: Target and type

\begin{tabular}{ll}
\hline Code & Description \\
$\begin{array}{l}\text { Reflective } \\
\text { Directed }\end{array}$ & $\begin{array}{l}\text { Decoupled from any other communicative act, not directed towards a team member } \\
\text { Specifically targeted at other team member(s), often associated with vocalisation of an } \\
\text { idea/explanation }\end{array}$ \\
\hdashline$-\begin{array}{c}\text { Iconic } \\
\text { Metaphoric }\end{array}$ & $\begin{array}{l}\text { Explanative motion and shapes of concepts e.g. explaining an idea } \\
\text { Beat }\end{array}$ \\
$\begin{array}{l}\text { Deictic } \\
\text { Cohesive }\end{array}$ & $\begin{array}{l}\text { Pointhing e.g. directing the gaze to a sketch or note } \\
\text { In addition to gesture it was also noted when the participants spoke in order to give a baseline }\end{array}$ \\
&
\end{tabular}

\subsubsection{Coding Function Behaviour Structure}

In terms of determining the design element of a gesture the situated FBS framework was adopted (Gero \& Kannengiesser, 2004). This allowed gestures to be related to core aspects of the design discussion. Here, the aim was to understand gesture sequences' roles in the coevolution of functions and parts, their relative behaviour, and associated physical structures. FBS provides a robust and general framework for decomposing these attributes in the design context, as highlighted by Eris et al. (2014). An alternative schema is provided by the Design Ontology developed by Storga et al. (2010) and refined by Ahmed and Storga (2009). However, this provides a highly detailed characterisation of engineering design elements, and thus excludes the wider roles of gesture, making it unsuitable for the current work.

Again, codes are complete and mutually exclusive. A mutually exclusive scheme was selected in order to improve the reliability of the coding, and in recognition of the fundamentality of the FBS framework, where a designer focuses on one element at a time. This does not mean changes in focus or groups of gestures were ignored, instead these were coded sequentially. For example, a participant raises his/her hands to signal a structural 
feature, and then, without returning to a neutral position, transitions into a functional demonstration. This would be coded as Structure immediately followed by Function with no gap between codes. Further this type of gesture would be associated with a continuous reflective or directed code. As such, transitions between framework elements can be described as sequential shifts between individually allocated gestures. For the purposes of this study FBS codes were applied to all gestures identified during the gesture coding (Section 3.2.1) except those classified as 'cohesive'. These were discarded at this stage, as they are concerned with conversational flow rather than the representation of concepts. The FBS codes used are detailed in Table 3, which has been drawn from the work of Gero and Kannengiesser (2004) and further highlighted as a next step in gesture research by Eris et al. (2014).

Table 3: FBS codes: Design element

\begin{tabular}{|c|c|}
\hline Code & Definition \\
\hline Requirement (R) & $\begin{array}{l}\text { Includes all requirements and constraints that are explicitly provided to the designer at the } \\
\text { outset of the design task } \\
\text { For example: references to the requirements document or other constraints of the task, } \\
\text { use of any briefing documents or other material handed out }\end{array}$ \\
\hline Function $(\mathbf{F})$ & $\begin{array}{l}\text { Includes teleological representations that can cover any expression related to potential } \\
\text { purposes of the design } \\
\text { For example: gestures relating to what the design will do - what it is for i.e. take photos, } \\
\text { user needs, use scenarios, 'its purpose' }\end{array}$ \\
\hline $\begin{array}{l}\text { Expected behaviour } \\
\text { (Be) }\end{array}$ & $\begin{array}{l}\text { Includes attributes of the design used as assessment criteria or target values for potential } \\
\text { design solutions. They may include technical, economic, ergonomic and other } \\
\text { characteristics } \\
\text { For example: gestures related to what the design does and how it does it in the context of } \\
\text { the internal characteristics of the design not based on extant concrete design } \\
\text { representations - what it does i.e. how the systems and components actually work to bring } \\
\text { about the function }\end{array}$ \\
\hline $\begin{array}{l}\text { Behaviour from } \\
\text { structure (Bs) }\end{array}$ & $\begin{array}{l}\text { Includes attributes of the design that are measured, calculated or derived from observation } \\
\text { of a specific design solution } \\
\text { For example: gestures related to what the design does based upon reference to previously } \\
\text { established structural characteristics }\end{array}$ \\
\hline Structure (S) & $\begin{array}{l}\text { Includes the components of a design and their relationships. They can appear either as a } \\
\text { set of general concept solutions or as detailed solutions } \\
\text { For example: the physical arrangement of components, subsystems or the design in } \\
\text { relation to each other and the external requirements - what it is }\end{array}$ \\
\hline $\begin{array}{l}\text { Design description } \\
\text { (D) }\end{array}$ & $\begin{array}{l}\text { Includes any form of external representation produced by a designer, at any stage of the } \\
\text { design process } \\
\text { For example: references to logbook sketches or the final design sketch, references } \\
\text { directed at any other physical representations of the design }\end{array}$ \\
\hline
\end{tabular}




\section{Results}

This section first gives a brief overview of individual gesture use for characterisation purposes before focusing on larger gesture sequences in Section 4.2.

\subsection{Individual Gesture Use}

This section outlines overall gesture use in the session. In line with previous works where baseline gesture use has been characterised e.g. Eris et al. (2014), Figures 4 and 5 summarise the mean duration (in terms of proportion of the session) of the gesture categories with respect to target (Figure 4) and design elements (Figure 5). Although conclusions can not be drawn from these results due to the sample size, they help situate the gesture sequences with respect other studies of gesture in the design domain. Further, they help contextualise the relative usage of gesture sequences verse individual gestures. With respect to the design elements, F, $\mathrm{Be}, \mathrm{Bs}$, and $\mathrm{S}$ were associated with iconic gesture use while deictic and beat type gestures linked to $\mathrm{R}$ and $\mathrm{D}$ elements (Figure 5). This is in contrast to the gesture sequences discussed in Section 4.2, which are associated with specific patterns of design activity e.g. the transition from function to structure.

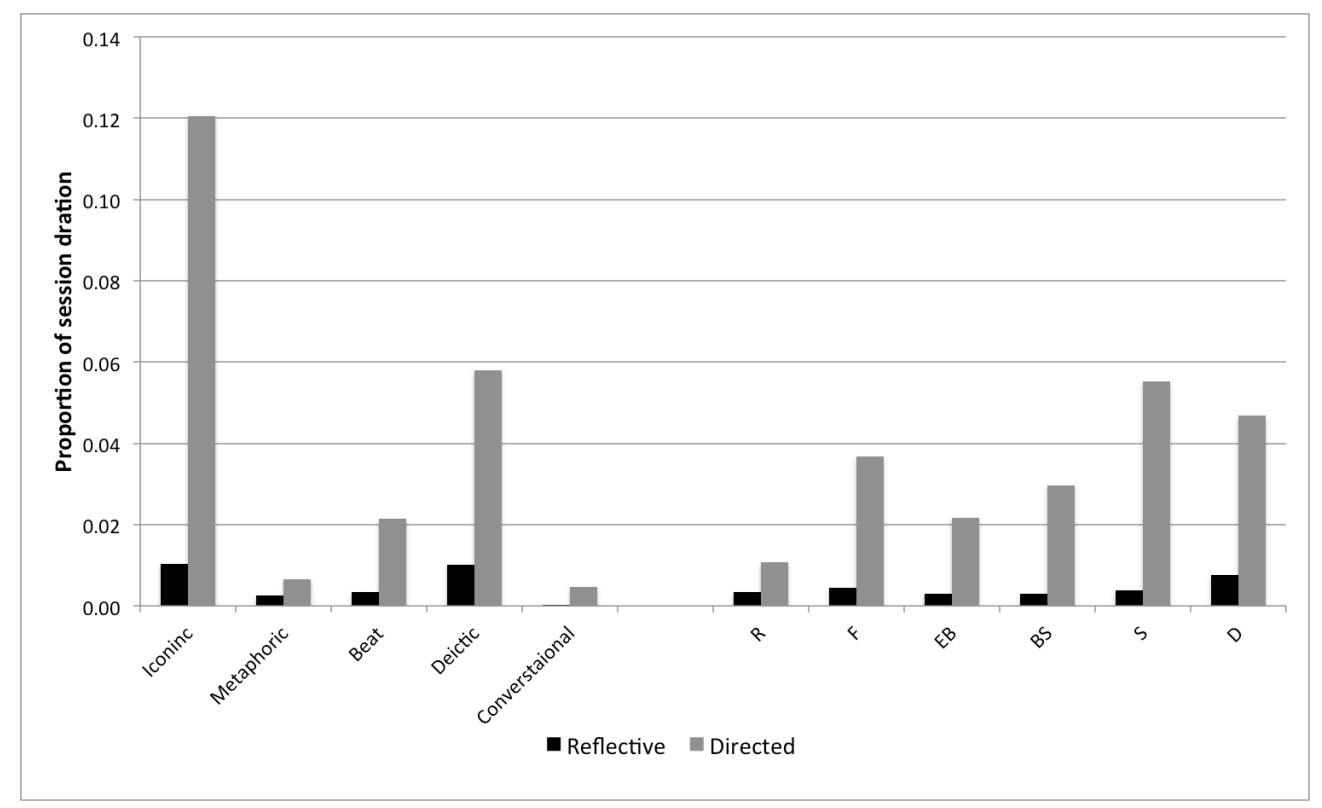


Figure 4: Distribution of reflective and directed gestures across the various gesture types

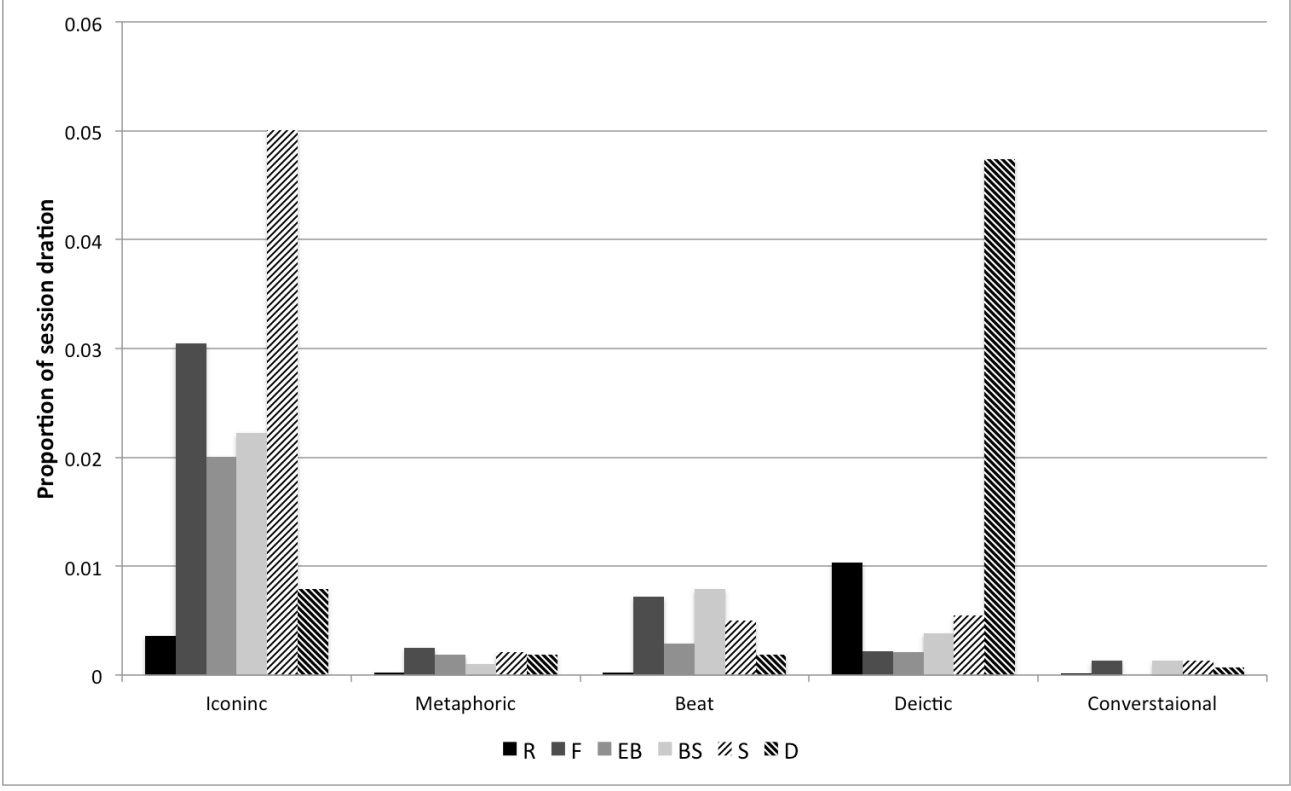

Figure 5: FBS design elements versus gesture type

Table 4 summarises the distribution of vocalisation, gesture, and simultaneous gesture and vocalisation in line with Eris et al. (2014). Circa 20\% of gestures occurred in isolation from vocalisation.

Table 4: Average distribution of activity across the participants

\begin{tabular}{lllll}
\hline & $\begin{array}{l}\text { Vocalisation } \\
\text { (as \% of session) }\end{array}$ & $\begin{array}{l}\text { Gesture } \\
\text { (as \% of session) }\end{array}$ & $\begin{array}{l}\text { Simultaneous } \\
\text { (as \% of session) }\end{array}$ & $\begin{array}{l}\text { Simultaneous } \\
\text { (as \% of gesture) }\end{array}$ \\
\hline Mean & 52.3 & 8.5 & 7.1 & 81.7 \\
Standard Deviation & 17.4 & 4.7 & 4.1 & 4.7 \\
\hline Finally, Figure 6 gives a timeline of gesture and vocalisation for each participant (bold lines \\
separate teams). Here it is possible to see the differences between individuals. For example, \\
participants 4 and 9 predominantly use simultaneous gesture and vocalisation while \\
participants 2 and 11 rely almost exclusive on vocalisation. This differentiation was not found \\
to link to any of the measured participant characteristics e.g. age, education level, and \\
experience.
\end{tabular}




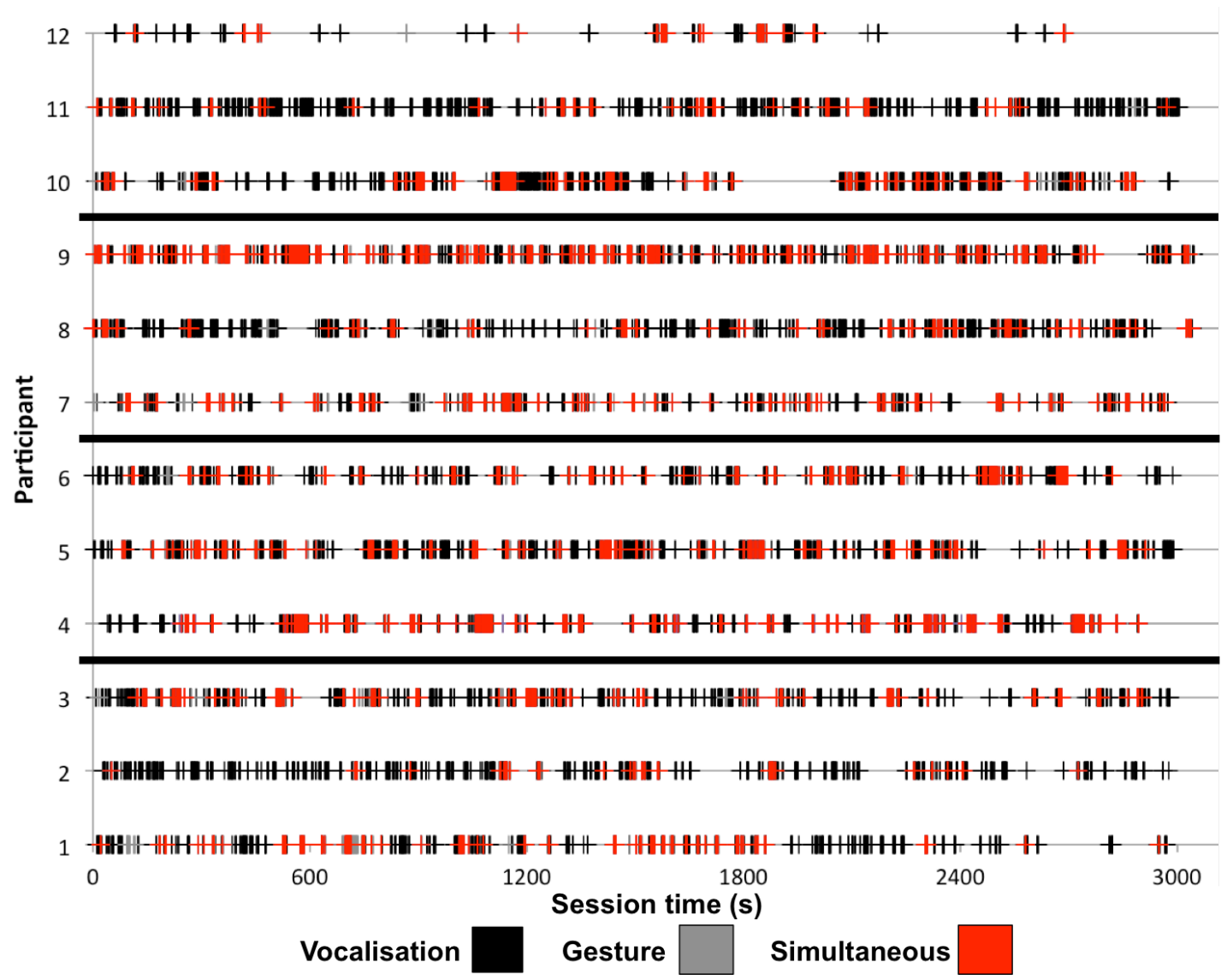

Figure 6: Vocalisation, gesture, and simultaneous gesture and vocalisation for each participant with respect to the session timeline, major markers are at ten minute intervals

\subsection{Gesture Sequences}

The focus of the data analysis was on the roles played by sequences of gestures (Section 3 ). Here, several sequences and their roles were distilled from the video using a grounded approach, in four steps:

1. The authors independently coded for distinct gesture sequences without assigning them categories.

2. The identified sequences were then discussed and grouped based on a holistic assessment of their characteristics to distil four manifest categories: compound reflection, compound directed one-way, mirroring, and modification (defined below).

3. These categories were then used to independently code all gesture sequences and intercoder reliability was assessed - giving a 100\% agreement, i.e. each grouping was distinct and identifiable across teams. 
4. Each identified gesture sequence was then analysed qualitatively in order to develop an understanding of their various roles in the design activity. Hence, their importance was gauged based on a holistic assessment of their specific impact on the design activity.

The gesture sequences constituted periods of continuous gesturing (as well as other interaction modes) dealing with design concepts. These were strongly related to the activity of the participants and were both common across teams and over the course of the session. Examining these periods in detail and comparing the found sequences with literature, the categories were named as follows:

- Compound reflection: physically acting out complex structures, mechanisms and other design concepts, by an individual participant, apart from the main conversation.

- Compound directed one-way: physically acting out complex structures and mechanisms in order to illustrate a number of related ideas or concepts to one or more team-members often coupled with other interaction modes, e.g. speech.

- Mirroring: team-members respond to a directed gesture by performing the same physical action themselves.

- Modification: team-members respond to a directed gesture by performing a new version of the gesture, either adding or removing elements.

These four sequence types appear to have specific roles in the design context. Although gestures were observed throughout the session as highlighted in Figure 6, these typically dealt with a single concept or design element. This is in contrast to the sequences where numerous concepts and design elements are related via longer strings of gestures and other interaction modes. The four sequences combined accounted for $6.2 \%$ of the session on average, and their distribution is summarised in Table 5. Although these instances are fleeting and account for only a small portion of the session their qualitative impact was substantial and common across teams, coinciding with key junctures in the design activity, illustrated in the following sub-sections. 
Table 5: Quantitative summary of the four sequence categories

\begin{tabular}{lllll}
\hline & $\begin{array}{l}\text { Compound } \\
\text { reflection }\end{array}$ & $\begin{array}{l}\text { Compound } \\
\text { directed }\end{array}$ & Mirroring & Modification \\
\hline Mean total duration (\% of the session) & 0.26 & 4.48 & 0.46 & 0.96 \\
Standard Deviation & 0.22 & 2.94 & 0.28 & 0.36 \\
Mean instance duration (seconds) & 7.9 & 11.9 & 5.5 & 7.7 \\
Standard Deviation & 4.6 & 9.3 & 4.1 & 4.2 \\
Mean instances per team & 1 & 11.3 & 2.5 & 3.8 \\
Standard Deviation & 0.8 & 6.7 & 1.9 & 1 \\
\hline
\end{tabular}

\section{Compound Reflection}

Although compound reflection sequences were not common in the data they were typically associated with moments of understanding development for the participant involved. In contrast to the more directed sequences it seems that reflective gestures are typically used to support understanding of a single concept or idea. Only four instances of compound reflection were observed (Table 5), however, they are noted here for their important function in the task. They were used when reflecting on complex structural elements in the design, in particular, trying to understand the various axes of movement and their interaction. These sequences were related specifically to FBS function and FBS structure. Figure 7a shows a generic template for how such sequences evolve using the motor positioning example outlined below. Further, Figure $7 \mathrm{~b}$ details a specific fragment from the session in order to illustrate how these sequences interface with the wider design activity.

Figure $7 \mathrm{~b}$ and Fragment 1 detail how a participant used gesture to understand a number of related design concepts in sequence. In the wider context of the design task, this participant used the understanding developed during this gesture sequence to drive the main ideation about the structure of the mounting framework and how movement would be achieved. In particular the sequence highlighted above was followed by sketched, vocal, and gestural explanation and development of the concept by the team. This formed a major element of the middle part of the design activity. During this reflective sequence 'Bill' explored how the camera cradle is shaped and subsequently how it will move around the axes of motion. Here the cradle is depicted in Figure 7b.i with a bowl type gesture of Bills hands - 
FBS structure. This is then followed by a rapid rotation round two axes as he maps out the movement space (Figure 7b.ii) - Shifting to exploring FBS behaviour from structure. Finally, he draws in the other participants by motioning towards previous sketches (Figure 7b.iii), and begins to sketch out his understanding of the structure and a potential means for its realisation. Bill's gestures are coupled with self-referential vocalisation and a gradual shift in the attention of the other team members as they begin to take notice of Bill's actions.
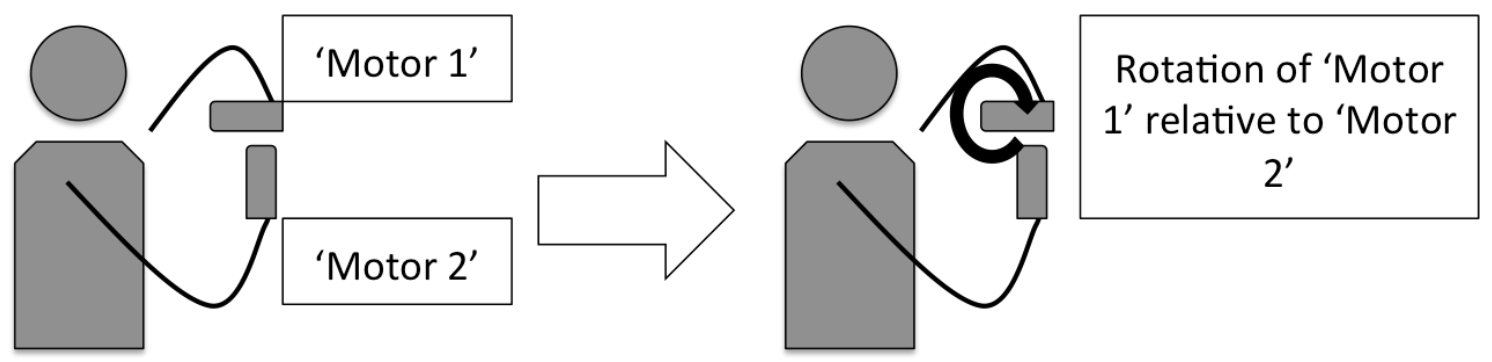

7a: Generic illustration of compound reflection
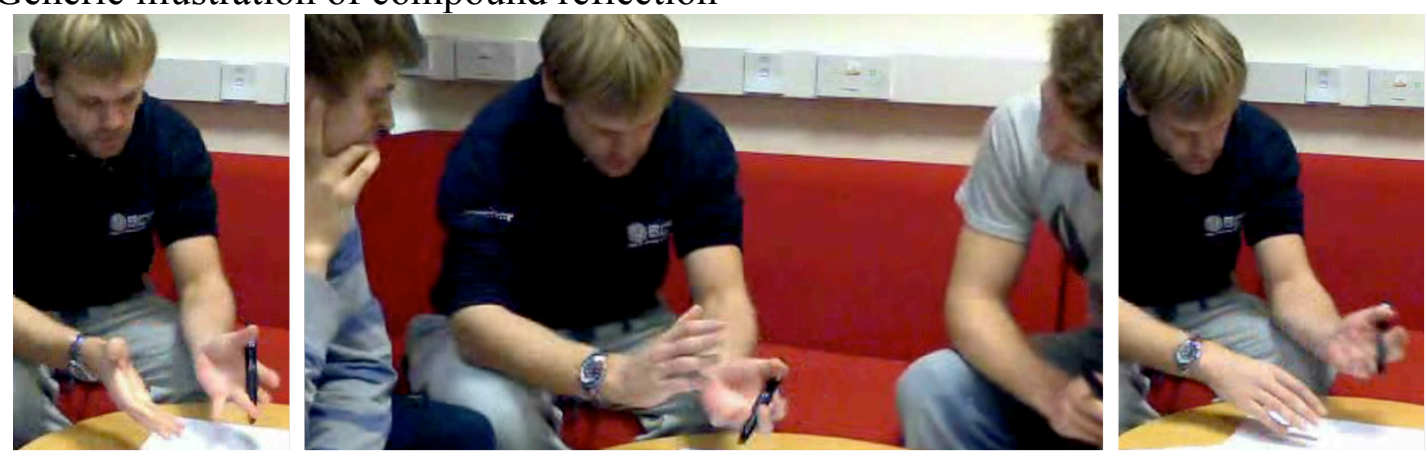

7b: Specific example of compound reflection during the design session. i) Bill explores how the camera cradle is structured ii) Bill considers the axis of movement iii) Bill refers to a previously sketched idea

Figure 7: The progression of a gesture Fragment 1: Team 2, 761-771 seconds (Figure 7b)

1 Bill there is also like umm... (Figure 7b.i)

2 Bill let me just think, how many axes do we need [very quietly] [team turn gaze towards gesturing] (Figure 7b.ii)

3 Bill [directs team to sketch paper] (Figure 7b.iii)

4 Bill yeah you could have gears... [transitions to directed]

\section{Compound Directed One-way}

Directed one-way sequences were again associated with a number of distinct roles in the design activity. This type of sequence was primarily linked to the description of complex 
spatial arrangements and relative movement, and often formed the culmination of prior discussion. In this regard three main roles emerged associated with FBS function and the connection from FBS behaviour to FBS structure:

1. The introduction of new core ideas and the subsequent spawning of idea families. These marked creative turning points in the ideation discussion e.g. exploring new fundamental concepts such as using gravity instead of motors to move the camera.

2. Key moments of clarification or agreement in the team. These agreements on e.g. $F B S$ function, could be traced to the final design output and the dominant ideas produced by the teams.

3. Coupling explanations of FBS function and FBS structure in relation to idea propositions. Ideas explained in this way were subsequently found in a high proportion of the designs created by the team, indicating their importance and acceptance in the group.

For example, directed one-way gestures were key to developing a shared understanding of both the structure and dynamic interfaces of the design - elements that are difficult to otherwise verbally describe and around which there was significant ambiguity. In this role, they formed a type of punctuation in the design activity, with a number of directed sequences concluding one topic of discussion and precipitating the move to a new aspect of the design.

Figure 8 and Fragment 2 describe one such sequence in order to illustrate this in practice. Here participant 'Jim' is explaining how the camera cradle is suspended from the balloon and how this could subsequently be used to achieve camera motion. This relates to Jim trying to describe the implications of various structures on the behaviour of the device i.e. FBS behaviour from structure. Jim starts by illustrating the previous discussions involving a wire type attachment, which also serves to draw the attention of the rest of the team (Figure 8.i). He then suggests an evolution of this idea where the attachment is a solid arm and directs his gaze at each team member (Figure 8.ii). He then illustrates a number of concepts for how 
this arm could be articulated including a solid actuator (Figure 8.iii), a current driven system (Figure 8.iv), and a ball joint system (Figure 8.v). Finally, he concludes by suggesting it could rotate like a worm by rotating his own arm is a circle with his hand extended (Figure 8.vi). This resulted in a detailed discussion of how this mechanism might be achieved and a period of sketching by the team, where the attachment mechanism is partially defined.
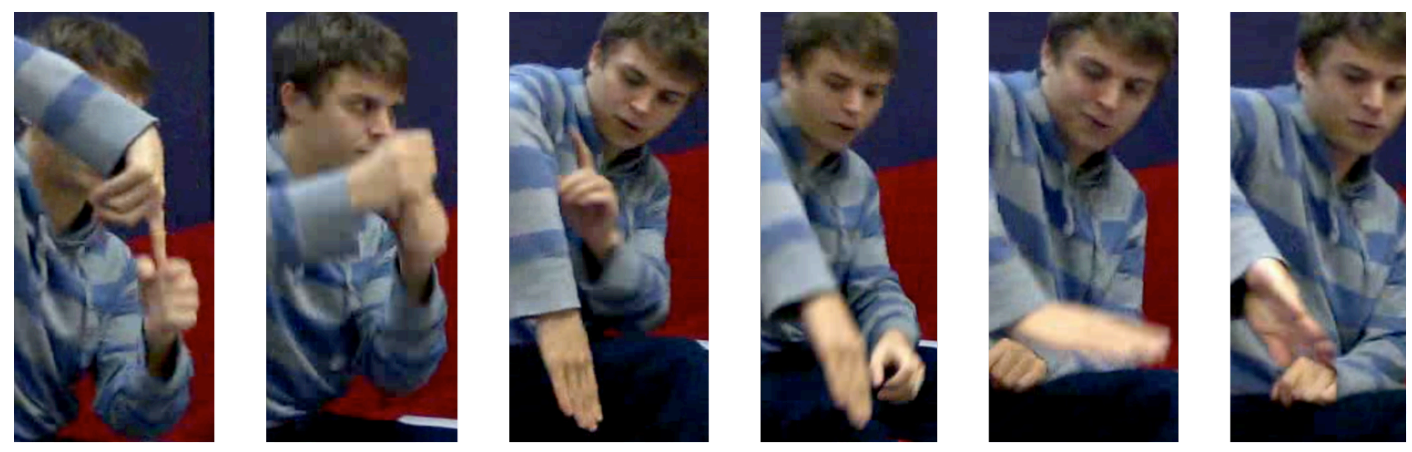

Figure 8: Specific example of compound directed one-way gesture during the design session. i) Jim initiates the interaction by showing the suspension for the camera ii) Jim clarifies this gesture from to be a solid, and shifts his gaze momentarily to the other team members iii) this transitions into the whole arm showing a solid connection iv) Jim shows 'current' running up and down his arm v) Jim moves his hand to show the axial movement of the mount vi) Jim concludes the interaction by showing the rotation element Fragment 2: Team 2, 565-578 seconds (Figure 8)

1 Jim literally just like a umm... [team turns gaze to Jim] (Figure 8.i and ii)

2 Jim ...like an arm going down (Figure 8.iii) which you can apply different currents to (Figure 8.iv)

$3 \mathrm{Jim} \quad \ldots$ or pull different things and it turns like that (Figure 8.v)

4 Jim like a worm sort of thing [team makes agreement sounds and shift gaze away from Jim to sketch paper] (Figure 8.vi)

\section{Mirroring}

Mirroring sequences were primarily associated with agreeing on final design elements and in reaching a group understanding. In particular mirroring was associated with two main roles, commonly bracketed by reflective gestures by both the initiator and the receiver. First, developing a shared understanding of FBS functions. Here, mirroring was associated with moments where the team clarified and agreed core functional descriptions. These were linked to both the design at hand e.g. the axes of motion, and the description of analogues products found during the information gathering phase e.g. explaining the function of a gyroscopic 
camera mount. Second, mirroring was commonly linked to explanations of FBS structure and FBS behaviour from structure. These were again used to describe and agree the workings of analogues products from the information gathering phase. Many of the features described in this way were later found in the ideas produced and selected by the team, suggesting their importance in the overall ideation discussion.

Figure $9 \mathrm{~b}$ and Fragment 3 describe one of the key 'joint understanding' situations during the process of Team 1. Here, the whole team is involved in a complex series of gestures instigated by Jane in order to clarify the various axes of camera motion. This sequence is preceded by a number of reflective gestures by Jane, and followed by team agreement realised in the form of a concluding sketch. This sequence was associated with FBS function. Jane first highlights the axes by positioning her hand vertically and then rotating through the various axes (Figure 9b.i). Tim and Bob then mirror this by also moving their hands through the various axes. In particular Bob closely follows the gesture of Jane while also counting out a number associated with each axis (Figures 9b.ii and iii). Jane then reiterates the gesture with Bob and Tim momentarily directing their gaze to her, presumably for confirmation of their action (Figures 9b.iv and v). Finally, the whole team turns their gaze to Bob who quickly repeats his original movements and then turns to sketch the agreed arrangement on the whiteboard (Figure 9b.v). This is a key moment in the progression of Team 1 as it marks the point at which they agree their first major design parameter i.e. how many movement axes are required and how they are conceptualised. This decision informs much of the discussion in the rest of the session, as well as the final designs produced by the team. This also forms an example where a number of sequence types are combined into a larger grouping as illustrated in Figure 9a. 

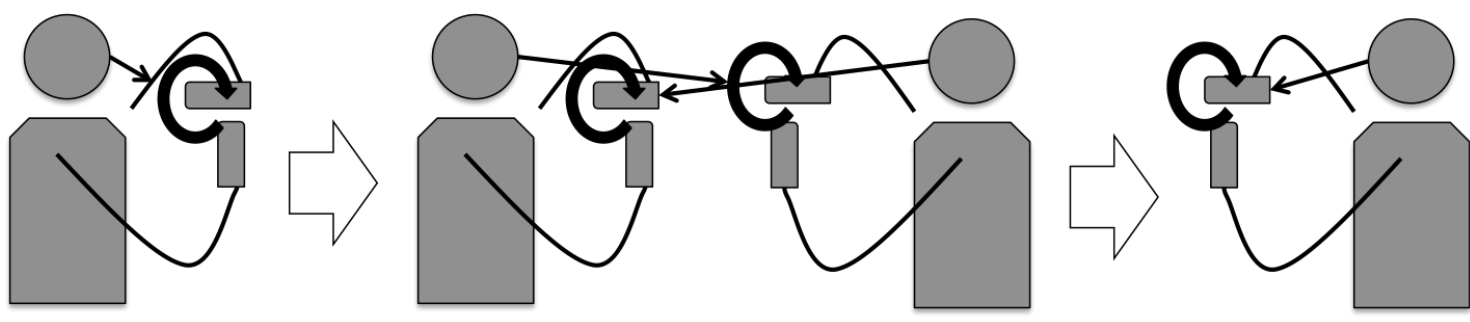

Reflection

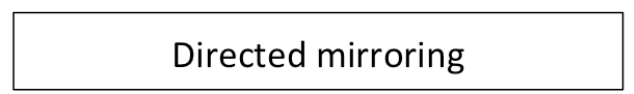

Reflection

9a: Generic illustration of mirroring
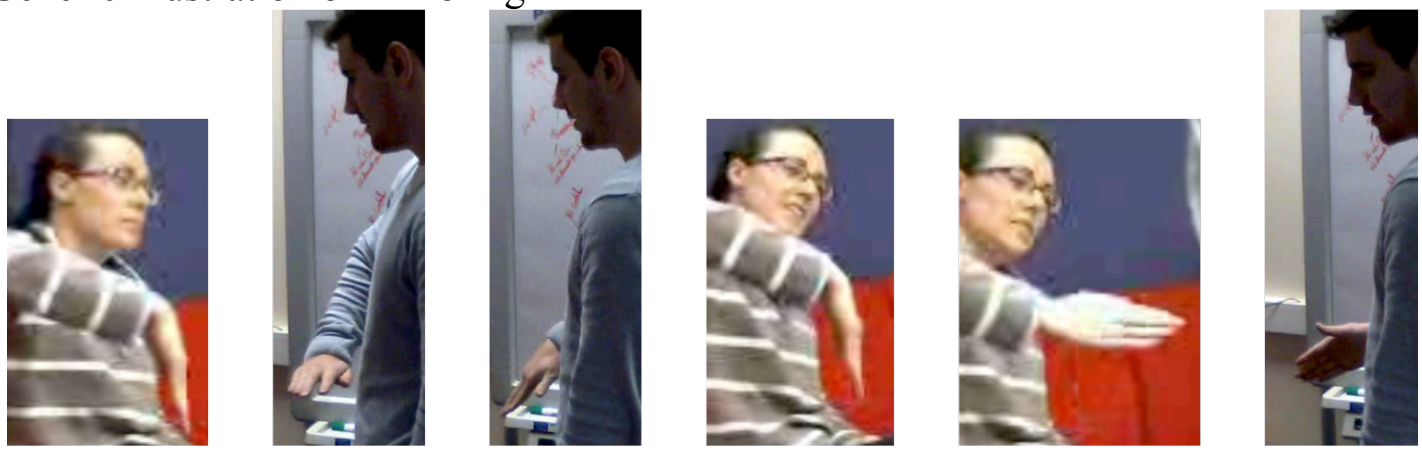

9b: Specific example of modification during the design session. i) Jane demonstrates the axes of motion ii and iii) Bob shows each axis while counting iv and v) Jane makes the same movements as Bob vi) Bob concludes the exchange by re-iterating Jane's movement

Figure 9: Gesture development and idea evolution via reflection bracketed mirroring of gestures

Fragment 3: Team 1, 721-732 seconds

1 Jane [brings attention to axis of motion - initiating the exchange] (Figure 9b.i)

2 Tim so which ones? It's a bit like that one...

3 Bob one, two... and then pan as well [team directs gaze at Bob] (Figures 9b.ii and iii)

4 Tim ok

5 Jane so [Tim shifts gaze momentarily to Jane] (Figures 9b.1v and v)

6 Bob so that's the ones they had, it means we don't have to have that... [team directs gaze at Bob] (Figure 9b.vi)

7 Bob so we could have... [turns away from team to whiteboard]

\section{Modification}

Modification type sequences were associated with idea generation and evolution as well as moments of agreement. Here, an initial gesture communicates a design idea or concept, which is then taken up by a second participant who reinterprets it, making his or her own changes, before the next participant does the same. These bouts of reciprocal gesturing often resulted in 
a dynamic evolution of the gesture (and subsequently the idea/concept) through the various team members until no further changes were forthcoming.

Modification was predominantly associated with two main roles. First, it was linked to moments of clarification related to FBS structure and FBS behaviour. Their subsequent referencing in later ideation and requirements discussions highlights the importance of these clarification moments. Second, modification sequences were linked to the introduction and exploration of new streams of ideas related to FBS structure and FBS behaviour. As such, they played an important role in the development of the ideation activity.

A generic example of such an evolution is illustrated in Figure 10a and again links to the concept of 'gesture propagation' illustrated in Figure 9. Figure $10 \mathrm{~b}$ and Fragment 4 illustrate a simple example of this type of sequence in the context of the design session. Here, Tom initiates the interaction by trying to visualise the motion of the camera when rotating 360 degrees over ten seconds (Figure 10b.i). This draws the gaze of Brian who also creates the same motion but significantly faster. Brian starts and finishes his rotation gesture during the first half of Tom's movement (Figures 10b.ii and iii). Finally, Tom finishes his gesture and makes a conclusion about the speed of the motion (Figure 10b.iv), which Brian subsequently agrees with. This sequence is concerned with the FBS function and FBS behaviour of the mount and forms one of the core design features agreed by the team.

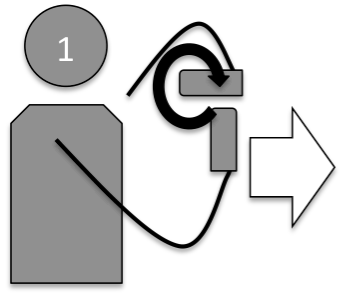

Initiate idea

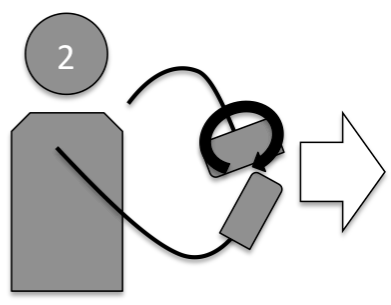

Modification 1

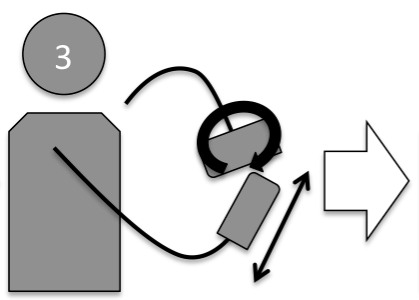

Modification 2

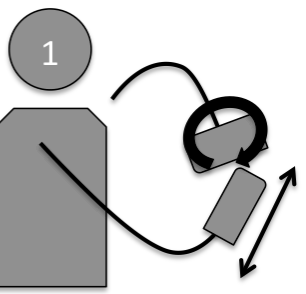

Mirroring agreement

10a: Generic illustration of modification 

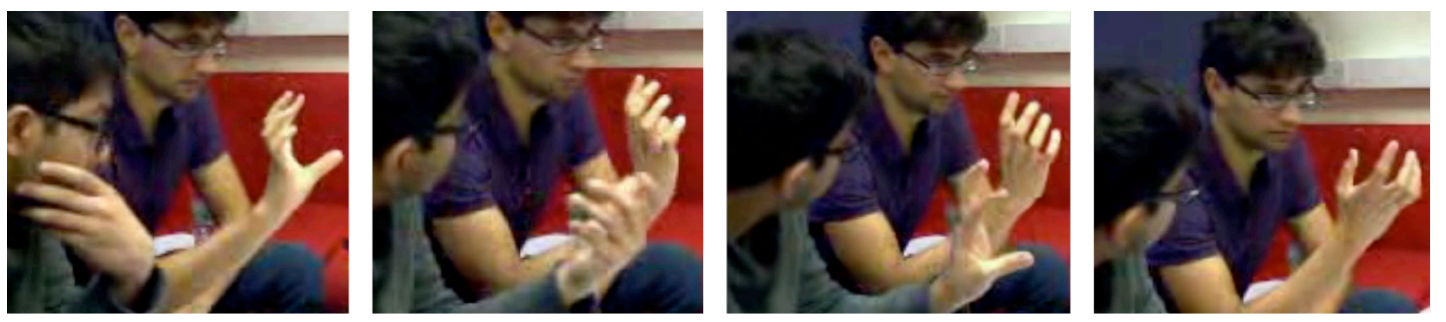

10b: Specific example of modification during the design session. i) Tom draws Brian's gaze and starts demonstrating a motor rotating the camera grip ii) Brian confirms his understanding by mimicking Tom's gesture iii) Brian does a fast rotation of his hand - much faster than Tom's movement iv) Tom concludes his rotation and makes a conclusion from exchange

Figure 10: Idea evolution via modification of gestures

Fragment 4: Team 3, 1985-1992 seconds

1 Tom in ten seconds it's going to go... [imitates motor noise](Figure 10b.i)

2 Brain [directs gaze at Tom's gesture] (Figure 10b.i)

2 Brian [turns towards Tom] so 360 (Figure 10b.ii)

3 Brian [completes hand movement] (Figure 10b.iii)

4 Tom nice and slow, nice and gentle (Figure 10b.iv)

\section{Combinations and Integration of Gesture with the Wider Activity}

Finally, it is important to consider the interaction between the proposed sequences and the wider session. Here, sequences were often dynamically combined during important periods of activity, particularly with regard to reaching agreement of design attributes or problems.

One example of such a combined sequence can be found in Team 1's discussion of the camera's axes of movement. Here, two sequences of compound directed are used to clarify the FBS function of the various axes, and then finalise agreement in the team (marked by notation of the axes in a sketch). This is immediately followed by a reflective sequence where one participant models the FBS function and FBS structure of the axes and motors resulting in the proposition a new concept that eliminates one axis. This proposition is supported by a compound directed sequence where the angle of rotation is clarified and the idea assessed. This combination of sequences formed a turning point in the discussion for Team 1 and the axes of movement agreed here were kept unchanged during the remaining design activity. 
This type of combined exchange is illustrated in Figure 11. In particular these combined sequences highlight the ability of participants to communicate complex multi element concepts within the team, both related to understanding and the FBS elements.

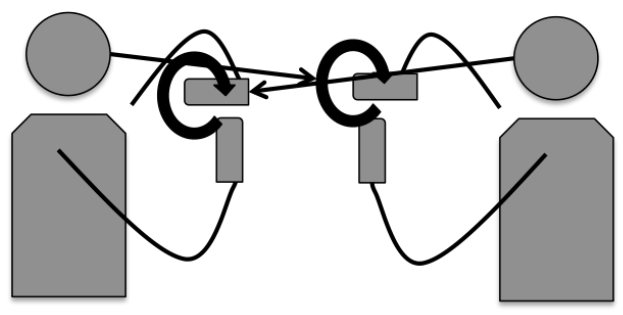

Compound directed

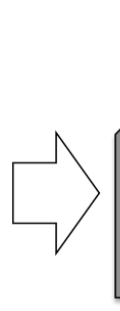

Reflection

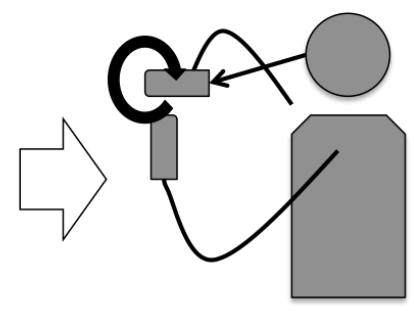

Compound directed and modification

Figure 11: An example of a dynamic combination of gestures at a key moment in the design process

Bringing together sequences and individual gestures Figure 12 shows that the distribution of the gesture sequences is less uniform than individual gestures. This also relates to the differing character of these activities, where individual gestures are used throughout the conversation gesture sequences are primarily associated with key turning points or other critical situations. Further, these situations involve complex multimodal exchange including gaze and vocalisation, as well as interactions with sketch paper or the whiteboard. It is important to note that these sketching media were typically used to finalise a point already discussed via gesture and speech rather than the core around which these discussions occurred, unlike Eris et al. (2014) or Luck (2010, 2014). Finally, Table 6 summarises the identified gesture sequences and their roles as observed in this study. 


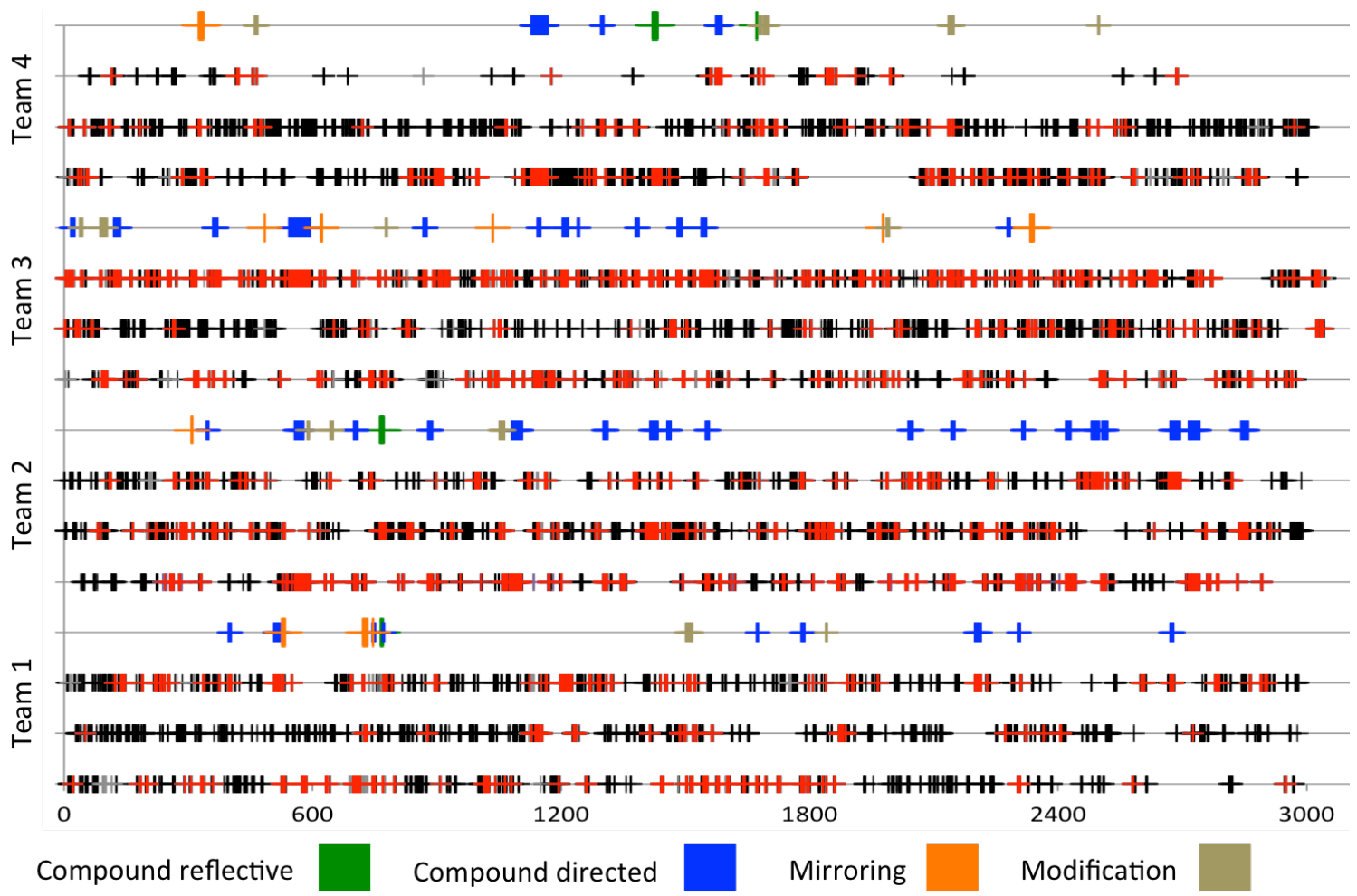

Figure 12: The four types of gesture sequence in relation to individual interactions (vocalisation, gesture, and simultaneous). Here the individual gesture timelines displayed in seconds (Figure 6) are compared to the use of gesture sequences. The gesture sequence data is displayed as fourth line above the individual gesture data from Figure 6 for each team

Table 6: Gesture sequences and observed roles

\begin{tabular}{ll}
\hline Sequence & Observed roles \\
\hline Compound reflective & Reflecting on complex structural elements related to FBS function and FBS structure. \\
Compound directed & The introduction of new core ideas and the subsequent spawning of idea families. \\
& Clarification or agreement in the team. \\
& Supporting influential ideas by coupling explanations of FBS function and FBS \\
& structure. \\
& Developing shared understanding of FBS function, in the design and in analogues \\
products. & \\
Mirroring & Explanations of FBS structure and FBS behaviour from structure, in the design and in \\
& Clarification of FBS structure and FBS behaviour. \\
& The introduction and exploration of new streams of ideas related to FBS structure and \\
Modification & FBS behaviour.
\end{tabular}

\section{Discussion}

Although individual gesture use is not the focus of this work the results outlined in Section 4.1 do contribute to the overall characterisation of gesture use in design teams. Here, there are two notable works that also describe gesture in this way: Eris et al. (2014) and Bekker et al. (1995). Bekker et al. also used teams of three and observed between 4 and 14 gestures per 
minute. In this study gesture use varied between 2 and 5 gestures per minute on average, although results for gesture use over time are similar i.e. it is continuous, throughout the session and is a core aspect of the face-to-face discussion (explored further in terms of the gesture sequences). In relation to Eris et al. (2014) key comparisons are the proportion of time spent gesturing and the proportion of gesture/vocalisation co-occurrence. In this study proportion of gesture use per participant is lower while the number of participants per team is higher (2 in Eris et al. (2014), 3 in this study). This suggests that, as with vocalisation, team size and individual contribution are negatively related (Gorla \& Lam, 2004). In contrast, both studies are aligned with respect to the high level of simultaneous gesture and vocalisation (90\% in Eris et al. (2014) and $82 \%$ in this study). Further, deictic gestures were found to be associated with directing attention to specific documents or design elements of interest to the initiator in line prior work (Donovan et al., 2011; Tversky, 2011; Visser \& Maher, 2011). Thus at the individual gesture level, the results reported here broadly align with prior findings of gesture use in design teams - although these are of limited number - setting the stage for the discussion of gesture sequences in this context.

It is well established that gestures are used in sequences (Luck, 2014; Visser, 2009; Yasui, 2013). However, substantial questions remain regarding their specific roles and characteristics in the design context. The sequence types proposed here build on the walkthrough concept described by Bekker et al. (1995) and serve to decompose this. Further, mirroring and modification are linked to the sequence types proposed by Yasui (2013). However, the four sequences proposed here extend Yasui's characterisation by explicitly integrating reflective practice, where no team interaction is involved, and expanding the scope of the sequences' roles in design practice beyond purely idea development. This wider characterisation of roles is reinforced in relation to design practice. 
With respect to compound reflection previous works have highlighted the importance of walkthrough type gestures for idea development (Yasui, 2013), generic design activity (Luck, 2010), and conversation management (Bekker et al., 1995). However, these characterisations have focused on gesture use directed towards other participants. In terms of supporting cognition, gesture has been shown to be important for planning out reasoning and speech (Alibali, Kita, \& Young, 2000), as well as in formulating and communicating mental simulations (Dow \& Klemmer, 2011). The distinct characterisation of reflective sequences associated with e.g. FBS function and FBS structure, links to this concept of supporting mental simulation and its specific relationship with the different aspects of design activity. This also highlights the distinct roles of gesture in comparison to other forms of design representation, such as, static sketches or physical prototypes. Here, the ability for participants to dynamically develop their reflective simulations and switch between different design elements is a key finding. In particular, this study points to reflective gesture as an important element in supporting the simulation of relative motion in real time and evolving this representation as physical interfaces are identified i.e. to 'prototype' with ones hands at critical junctures in the design activity.

With respect to compound directed the results from this study align with and add to the findings of Luck (2010) and Visser (2009) who also identified gesture sequences marking important junctures in the design session. In particular, their function in helping the team move between FBS behaviour and FBS structure was associated with key moments of clarification and agreement. Further, these results extend Luck (2010) and Yasui's (2013) discussion of the link between this type of gesture sequence and idea development. The results outlined here suggest that beyond simply being associated with idea development, gestural sequences are critically linked to the introduction of influential new concepts that subsequently spawn new streams of ideas. In particular, ideas introduced via gesture 
sequences that combined representations of both FBS function and FBS structure were predominantly found in the final design proposals. It is possible that this enhancement of an idea's influence links to Tang's (1991) finding that participants gesturing improves their subsequent ability to recall the associated ideas. This extends the arguments of Luck (2010) and Yasui (2013) to suggest that the coupling of gesture and idea initiation has a distinct influence in the design activity. Gesture allows participants to fully realise and communicate the fundamental elements of an idea, independent from sketching or other more traditional design representations. This builds on previous works where physical mediators have been characterised in this role (Crilly, Maier, \& Clarkson, 2008; Eris et al., 2014; Luck, 2014).

With respect to mirroring this study brings together the findings of Luck (2010), Lerner (1991), and Yasui (2013) who link mirroring to shared understanding and idea development. The characterisation of theses sequences aligns with fundamental interpretations of communicative acts where meaning is developed and informed by all communicating parties (Luck, 2010; Maier, Eckert, \& Clarkson, 2005). This also points to the varied roles of gesture in supporting the communication of complex structural and behavioural features, which are often difficult via other media, such as, physical prototypes (Boujut \& Blanco, 2003) or sketches (Eris et al., 2014). It is further possible that just as cognition can be embodied by gestures (Eckert \& Boujut, 2003), repeating a gesture triggers that cognitive structure in the recipient via motor cognition (Kilner, Paulignan, \& Blakemore, 2003). In this context there is a close conceptual link between this type of gesture sequence and modification or 'idea propagation' i.e. how designers learn and understand physical systems (J. Tang, 1991).

Modification sequences were associated with both moments of clarification, linking to Luck's (2014) characterisation, and the development of ideas, linking to Yasui's (2013) characterisation. However, the instantiations observed in this study were closely related to 
understanding of the design artefact and were not tied to design drawings or sketching activity. This type of gesture sequence appears to be intrinsically linked to idea propagation and evolution, and facilitating rapidly evolving shared understanding. This is a key element in design team performance (McDonnell, 2012; Mulder, Swaak, \& Kessels, 2002) and also relates to the concept of communicating 'indefinite precision' explained by Luff et al. (2009) and used by Luck (2014).

\subsection{Implications}

This study results in a number of implications for both design researchers and practitioners.

First, this work extends characterisations of gesture sequences in design activity to bring together both reflective and directed sequences and to highlight their interconnectivity with respect to each other, and wider vocalisation. In particular, four common sequence structures were observed, each associated with a number of distinct roles in the design activity, going beyond previous characterisations, e.g. the association between gestural sequences and the introduction of core ideas and the specific clarification of their functional and structural characteristics.

Second, this work has explored the links between gesture sequence use and the FBS framework. Here, the various sequence types bring together different aspects of the FBS framework to affect a range of outcomes in the design development and wider design activity. In particular, gesture sequences were linked to the clarification of functions, and the transition between structure and behaviour. Of particular note is the influence of ideas introduced through gestural sequences combing both functional and structural explanations.

Third, this study suggests that sequences are not only important for idea development but have a complex relationship that affects how ideas are adopted and agreed upon within a design team. As such, there is significant scope for further exploration of design specific 
gestures and their various roles in design performance - particularly in situations where prepared design documents are not the focus of the interaction.

Finally, there is a strong conceptual link between gesture use and the development of shared understanding. In particular the mirroring and modification type sequences were associated with the team agreeing foundational knowledge in order to support the design process. Thus, there is a clear need for further investigation as to how this shared understanding develops and how it can be supported by gesture sequences at key points in the discussion, particularly with respect to the different design elements.

\subsection{Limitations}

There are a number of limitations worth discussing with regards to the study and outlined findings.

First, the study focused on a specific electro-mechanical design task (the aerial camera mount), requiring consideration of the physical challenges associated with the design. There was little speculative discussion of difficult abstract concepts or the need to interpret metaphoric ideas such as in the film design example of Yasui (2013). Further, there was only limited use of sketching and no use of pre-prepared drawings. However, although it is apparent that task influences gesture use, the baseline agreement between the results reported here and e.g. Yasui (2013), Luck (2010) and Eris et al. (2014), lends empirical support to the robustness of the findings. Further, as the task has been previously explored in a number of empirical contexts and is drawn from observation of practice there is support for its applicability in this study.

Second, the characteristics of the task describe a specific context e.g. using students, the time allocation, and structure of the instructions. However, as with the task description these features are empirically supported by prior studies. Further, they are in line with the 
core works on gesture in the design domain. For example, Yasui (2013) used similar ideation instructions, student participants, and gave 45 minutes for their task. Eris et al. (2014) also used student teams over a period of approximately 30 minutes with no explicit methods guiding their ideation. Not considered here is the role of national or other cultural characteristics. Although these have been primarily linked to cohesive and social gestures (Archer, 1997) the authors are not aware of works that have compared design specific gesture across cultures, and thus do not have a basis for discussion or generalisation in this context.

Finally, the design of the study did not readily allow the participants to use physical prototypes or other objects in their discussions (although sketching was utilised). It is possible that the introduction of intermediary objects or physical materials for joint design would change the dynamic of the gestures being used - although it is unlikely in the extreme that they would eliminate gestures in this context (J. Tang, 1991). This was a deliberate choice, again linked to prior empirical characterisations of the task, in order to focus on gesture use in this context. As such, there is a need for further research in more complex design situations. This also links to studies in the architectural domain where several authors have highlighted the role pre-prepared drawings play in discussions.

\section{Conclusions}

This work investigated the varied roles of gestural sequences in design activity. This contributes to understanding of the links between gesture use and specific design elements using the FBS framework. In particular, this study explored how designers discuss, instigate, and virtually prototype ideas with their hands. In order to achieve this, an exploratory descriptive study was used, which focused on an electro-mechanical design task at the ideation stage. 
The study confirmed that gesture plays a range of roles in design situations, and highlighted four distinct gesture sequences (compound reflective, compound one-way directed, mirroring, and modification) that were associated with a number of roles in the design activity. This supports and extends extant work by characterising the integration of these sequences in the wider conversation, and their relationship with the FBS design elements. In particular, these findings highlight the link between core ideas and turning points in the design discussion, and specific gesture sequences e.g. the agreement of core functions, or the introduction of new lines of ideas.

Although there are a number of limitations associated with this study the findings presented here hold significant implications for both design researchers, and those seeking to support design in practice. By extending understanding and characterisations of gestural sequences, their varied roles, and link to FBS elements, new avenues are opened for developing support for the use of gesture in design activity, and it's training in the design classroom.

\section{References}

Ahmed, S., \& Storga, M. (2009). Merged ontology for engineering design: Contrasting empirical and theoretical approaches to develop engineering ontologies. Al EDAM (Artificial Intelligence for Engineering Design, Analysis and Manufacturing), 23(4), 391-407.

Alibali, M. W., Kita, S., \& Young, A. J. (2000). Gesture and the process of speech production: We think, therefore we gesture. Language and Cognitive Processes, 15(6), 593-613. doi:10.1080/016909600750040571

Archer, D. (1997). Unspoken diversity: Cultural differences in gestures. Qualitative Sociology, 20(1), 79-105. Retrieved from http://link.springer.com/article/10.1023/A:1024716331692

Ariff, N. S. N. A., Eris, O., \& Badke-Schaub, P. (2013). How Designers Express Agreement. In 5th IASDR Conference (pp. 1-10). Tokyo, Japan. Retrieved from http://repository.tudelft.nl/assets/uuid:64604893-ce58-4db5-b716-ea2b6e01d788/298529.pdf

Becvar, A., Hollan, J., \& Hutchins, E. (2008). Representational gestures as cognitive artifacts for developing theories in a scientifc laboratory. In M. S. Ackerman, C. A. Halverson, T. Erickson, \& 
W. A. Kellogg (Eds.), Resources, Co-Evolution and Artifacts (pp. 117-143). Springer. Retrieved from http://link.springer.com/chapter/10.1007/978-1-84628-901-9_5

Behoora, I., \& Tucker, C. S. (2015). Machine learning classification of design team members' body language patterns for real time emotional state detection. Design Studies, 39(July), 100-127. doi:10.1016/j.destud.2015.04.003

Bekker, M. M., Olson, J. S., \& Olson, G. M. (1995). Analysis of gestures in face-to-face design teams provides guidance for how to use groupware in design. In DIS '95 Proceedings of the 1st conference on Designing interactive systems: processes, practices, methods, \& techniques (pp. 157-166). New York, US: ACM.

Boujut, J.-F., \& Blanco, E. (2003). Intermediary objects as a means to foster co-operation in engineering design. Computer Supported Cooperative Work (CSCW), 12(2), 205-219. Retrieved from http://dx.doi.org/10.1023/A:1023980212097

Cash, P., Elias, E. W. A., Dekoninck, E., \& Culley, S. J. (2012). Methodological insights from a rigorous small scale design experiment. Design Studies, 33(2), 208-235.

Cash, P., Hicks, B. J., \& Culley, S. J. (2013). A comparison of designer activity using core design situations in the laboratory and practice. Design Studies, 34(5), 575-611. doi:http://dx.doi.org/10.1016/j.destud.2013.03.002

Cash, P., \& Snider, C. (2014). Investigating design: A comparison of manifest and latent approaches. Design Studies, 35(5), 441-472. Retrieved from http://www.sciencedirect.com/science/article/pii/S0142694X14000295

Caso, L., Maricchiolo, F., \& Bonaiuto, M. (2006). The impact of deception and suspicion on different hand movements. Journal of Nonverbal Behaviour, 30(1), 1-19. Retrieved from http://link.springer.com/article/10.1007/s10919-005-0001-z

Chang, Y. J., Chen, S. F., \& Huang, J. D. (2011). A Kinect-based system for physical rehabilitation: A pilot study for young adults with motor disabilities. Research in Developmental Disabilities, 32(6), 2566-2570. Retrieved from http://www.sciencedirect.com/science/article/pii/S0891422211002587

Crilly, N., Maier, A. M., \& Clarkson, P. J. (2008). Representing Artefacts as Media: Modelling the Relationship Between Designer Intent and Consumer Experience. International Journal of Design, 2(3), online. Retrieved from http://www.ijdesign.org/ojs/index.php/IJDesign/article/view/429

Cross, N., Dorst, K., \& Roozenburg, N. (1992). Research in Design Thinking. Delft, The Netherland: Delft University Press.

Donovan, J., Heinemann, T., Matthews, B., \& Burr, J. (2011). Getting the point: The role of gesture in managing intersubjectivity in a design activity. Artificial Intelligence for Engineering Design, Analysis and Manufacturing, 25(3), 221-235. Retrieved from http://journals.cambridge.org/abstract_S0890060411000059 
Dow, S. P., \& Klemmer, S. R. (2011). The Efficacy of Prototyping Under Time Constraints. In H. Plattner, C. Meinel, \& L. Leifer (Eds.), Design Thinking: Understand - Improve - Apply (pp. 111128).

Eckert, C., \& Boujut, J.-F. (2003). The role of objects in design co-operation: communication through physical or virtual objects. Computer Supported Cooperative Work (CSCW), 12(2), 145-151. Retrieved from http://www.springerlink.com/index/nOrm31423k691216.pdf

Eisenhardt, K. M., \& Graebner, M. E. (2007). Theory building from cases: Opportunities and challenges. Academy of Management Journal, 50(1), 25-32.

Eris, O., Martelaro, N., \& Badke-Schaub, P. (2014). A comparative analysis of multimodal communication during design sketching in co-located and distributed environments. Design Studies, In Press, 1-34. doi:10.1016/j.destud.2014.04.002

Gero, J. S. (1990). Design prototypes: a knowledge representation schema for design. Al Magazine, 11(4), 26.

Gero, J. S., \& Kannengiesser, U. (2004). The situated function-behaviour-structure framework. Design Studies, 25(4), 373-391.

Goldin-Meadow, S. (1999). The role of gesture in communication and thinking. Trends in Cognitive Sciences, 3(11), 419-429. Retrieved from http://www.ncbi.nlm.nih.gov/pubmed/10529797

Goldin-Meadow, S. (2005). Hearing gesture: How our hands help us think. First Harvard UNiversity Press. Retrieved from http://books.google.co.uk/books?hl=en\&lr=\&id=LCJ5eQdsolsC\&oi=fnd\&pg=PR9\&dq=\%22sche mes+for+classifying+types+of+gestures\%22\&ots=XLmJ4Xn721\&sig=Mbrn-aY8-

DuqBWVshfkRJwbNzZA

Gorla, N., \& Lam, Y. W. (2004). Who should work with whom?: Building effective software project teams. Communications of the ACM, 47(6), 79-82. Retrieved from http://sfxhosted.exlibrisgroup.com/bath?sid=google\&auinit=N\&aulast=Gorla\&atitle=Who should work with whom?: building effective software project teams\&id=doi:10.1145/990680.990684\&title=Communications of the ACM\&volume $=47 \&$ issue $=6 \&$ date $=2004 \&$ spage $=79 \&$ issn $=0001-0782$

Hackman, J. R., \& Vidmar, N. (1970). Effects of size and task type on group performance and member reactions. Sociometry, 33(1), 37-54.

Howard, T. J., Culley, S. J., \& Dekoninck, E. (2010). Reuse of ideas and concepts for creative stimuli in engineering design. Journal of Engineering Design, 22(8), 565-581. Retrieved from http://sfx4.exlibrisgroup.com/bath?sid=google

Kendon, A., \& Muller, C. (2001). Introducing gesture. Gesture, 1(1), 1-7. Retrieved from http://scholar.google.co.uk/scholar?hl=en\&q=Kendon+A\%2C+Muller+C+\%282001\%29+Introduc ing\%3A+GESTURE.+Gesture+1\%281\%29\%3A+1\%E2\%80\%937.+\&btnG=\&as_sdt=1\%2C5\&as_sdt $\mathrm{p}=\# 0$ 
Kilner, J. M., Paulignan, Y., \& Blakemore, S. J. (2003). An interference effect of observed biological movement on action. Current Biology, 13(6), 522-525. Retrieved from http://www.sciencedirect.com/science/article/pii/S0960982203001659

LeBaron, C., \& Streeck, J. (2000). Gestures, knowledge, and the world. In D. McNeill (Ed.), Language and gesture (pp. 118-138). Retrieved from https://books.google.co.uk/books?hl=en\&lr=\&id=DRBcMQuSrf8C\&oi=fnd\&pg=PA118\&dq=gest ures+knowledge+and+the+world\&ots=jCCX9yvmio\&sig=BJiuz4IgBS7zZy6f35attwhY4Uc

Lerner, G. (1991). On the syntax of sentences-in-progress. Language in Society, 20(3), 441-458.

Luck, R. (2010). Using objects to coordinate design activity in interaction. Construction Management and Economics, 28(6), 641-655. Retrieved from http://www.tandfonline.com/doi/abs/10.1080/01446193.2010.489924

Luck, R. (2014). Seeing architecture in action: designing, evoking, and depicting space and form in embodied interaction. International Journal of Design Creativity and Innovation, 2(3), 165-181. doi:10.1080/21650349.2013.875488

Luff, P., Heath, C., \& Pitsch, K. (2009). Indefinite precision: Artefacts and interaction in design. In C. Jewitt (Ed.), The Routledge handbook of multimodal analysis (pp. 213-224). Abingdon, UK: Routledge.

Maier, A. M., Eckert, C. M., \& Clarkson, P. J. (2005). A meta-model for communication in engineering design. CoDesign, 1(4), 243-254. Retrieved from http://www.tandfonline.com/doi/abs/10.1080/15710880500478353

Maier, A. M., \& Kleinsmann, M. (2013). Studying and supporting design communication. Artificial Intelligence for Engineering Design, Analysis and Manufacturing, 27(2), 87-90. Retrieved from http://journals.cambridge.org/abstract_S0890060413000139

McDonnell, J. (2012). Accommodating disagreement: A study of effective design collaboration. Design Studies, 33(1), 44-63. Retrieved from http://www.sciencedirect.com/science/article/pii/S0142694X1100038X

McNeill, D. (1992). Hand and Mind. In What gestures reveal about thought (pp. 75-104). London, UK. Retrieved from http://scholar.google.com/scholar?hl=en\&btnG=Search\&q=intitle:Hand+and+Mind\#4

McNeill, D. (2000). Language and gesture. Cambridge UK: Cambridge University Press. Retrieved from http://books.google.co.uk/books?hl=en\&lr=\&id=DRBcMQuSrf8C\&oi=fnd\&pg=PR9\&dq=Languag e+and+Gesture\&ots=jCzU7uprpl\&sig=h5C1rXVggn4QqFAmzjHH9VVE3R4

Mitra, S., \& Acharya, T. (2007). Gesture recognition: A survey. Systems, Man, and Cybernetics, Part C: ..., 37(3), 311-324. Retrieved from http://ieeexplore.ieee.org/xpls/abs_all.jsp?arnumber=4154947

Mulder, I., Swaak, J., \& Kessels, J. (2002). Assessing group learning and shared understanding in technology-mediated interaction. Journal of Educational Technology \& Society, 5(1), 35-47. Retrieved from http://sfx4.exlibrisgroup.com:9003/bath?sid=google 
Murphy, K. M. (2005). Collaborative imagining: The interactive use of gestures, talk, and graphic representation in architectural practice. Semiotica, 2005(156), 113-145. Retrieved from http://www.degruyter.com/view/j/semi.2005.2005.issue-

156/semi.2005.2005.156.113/semi.2005.2005.156.113.xml

Murphy, K. M., Ivarsson, J., \& Lymer, G. (2012). Embodied reasoning in architectural critique. Design Studies, 33(6), 530-556. doi:10.1016/j.destud.2012.06.005

Peter, A., Lotz, N., McDonnell, J., \& Lloyd, P. (2013). The effect of prototyping material on verbal and non-verbal behaviours in collaborative design tasks. In 5th IASDR Conference (pp. 2383-2394). Tokyo, Japan. Retrieved from http://oro.open.ac.uk/38801/

Rodgers, P. (Ed.). (2012). Articulating Design Thinking. Faringdon, UK: Libri Publishing.

Roth, W.-M. (2001). Gestures: Their Role in Teaching and Learning. Review of Educational Research, 71(3), 365-392. doi:10.3102/00346543071003365

Salas, E., DiazGranados, D., Klein, C., Burke, C. S., Stagl, K. C., Goodwin, G. F., \& Halpin, S. M. (2008). Does team training improve team performance? A meta-analysis. Human Factors, 50(6), 903933. Retrieved from

http://sfxhosted.exlibrisgroup.com/bath?sid=google\&auinit=E\&aulast=Salas\&atitle=Does team training improve team performance? A metaanalysis\&id=doi:10.1518/001872008X375009\&title=Human Factors \&volume $=50 \&$ issue $=6 \&$ date $=2008 \&$ spage $=903 \&$ issn $=0018-7208$

Schön, D. A., \& Wiggins, G. (1992). Kinds of seeing and their functions in designing. Design Studies, 13(2), 135-156.

Storga, M., Andreasen, M. M., \& Marjanovic, D. (2010). The design ontology: Foundation for the design knowledge exchange and management. Journal of Engineering Design, 21(4), 427-454.

Streeck, J. (2008). Depicting by gesture. Gesture, 8(3), 285-301. doi:10.1075/gest.8.3.02str

Streeck, J. (2009). Gesturecraft: The manu-facture of meaning. Amsterdam, The Netherlands: John Benjamins Publishing Company. Retrieved from http://books.google.co.uk/books?hl=en\&lr=\&id=IUl5mZRie6gC\&oi=fnd\&pg=PR1\&dq=Streek, +2 009:+Gesturecraft.+\&ots=bQial8CHkI\&sig=N5kF4VQI8X9nt6xV1VsWNAVOFOM

Tang, H. H., Lee, Y. Y., \& Gero, J. S. (2011). Comparing collaborative co-located and distributed design processes in digital and traditional sketching environments: A protocol study using the functionbehaviour-structure coding scheme. Design Studies, 32(1), 1-29. Retrieved from http://www.sciencedirect.com/science/article/B6V2K-50PB9N0-

1/2/1c22277cd4aeda5a95a3dc3791daee9d

Tang, J. (1991). Findings from observational studies of collaborative work. International Journal of Man-Machine Studies, 34(2), 143-160. Retrieved from http://www.sciencedirect.com/science/article/pii/002073739190039A

Tversky, B. (2011). Visualizing thought. Topics in Cognitive Science, 3(3), 499-535. Retrieved from http://onlinelibrary.wiley.com/doi/10.1111/j.1756-8765.2010.01113.x/full 
Visser, W. (2009). Form and function of gestures in an architectural design meeting. In J. McDonnell \& P. Lloyd (Eds.), About Designing: Analysing Design Meetings (pp. 269-284). London, UK: Taylor \& Francis.

Visser, W. (2010). Function and form of gestures in a collaborative design meeting. In S. Kopp \& I. Wachsmuth (Eds.), Gesture in embodied communication and human-computer interaction. 8th international getsure workshop (pp. 61-72). Bielefeld, Germany: Springer Berlin Heidelberg. Retrieved from http://link.springer.com/chapter/10.1007/978-3-642-12553-9_6

Visser, W., \& Maher, M. L. (2011). The role of gesture in designing. Guest editorial. Al EDAM (Artificial Intelligence for Engineering Design, Analysis and Manufacturing), 25(3), 213-220.

Wachs, J. P., Kölsch, M., Stern, H., \& Edan, Y. (2011). Vision-based hand-gesture applications. Communications of the ACM, 54(2), 60-71. Retrieved from http://dl.acm.org/citation.cfm?id=1897838

Waldherr, S., Romero, R., \& Thrun, S. (2000). A gesture based interface for human-robot interaction. Autonomous Robots, 9(2), 151-173. Retrieved from http://link.springer.com/article/10.1023/A:1008918401478

Wilson, M. (2002). Six views of embodied cognition. Psychonomic Bulletin \& Review, 9(4), 625-636. Retrieved from http://link.springer.com/article/10.3758/BF03196322

Yasui, E. (2013). Collaborative idea construction: Repetition of gestures and talk in joint brainstorming. Journal of Pragmatics, 46(1), 157-172. doi:10.1016/j.pragma.2012.10.002 